\title{
SLM 125 SINGLE TRACK AND DENSITY CUBE CHARACTERIZATION FOR 316L STAINLESS STEEL
}

\author{
A Thesis \\ presented to \\ the Faculty of California Polytechnic State University, \\ San Luis Obispo
}

\author{
In Partial Fulfillment \\ of the Requirements for the Degree \\ Master of Science in Industrial Engineering
}

by

Cullen Goss

June 2019 
(C) 2019

\section{Cullen Goss}

ALL RIGHTS RESERVED 
TITLE: SLM 125 Single Track and Density Cube Characterization for 316L Stainless Steel

AUTHOR: Cullen Goss

DATE SUBMITTED: June 2019

COMMITTEE CHAIR: $\quad$ Xuan Wang, Ph.D., Professor of IndustrialManufacturing Engineering

COMMITTEE MEMBER: Jose Macedo, Ph.D., Professor of IndustrialManufacturing Engineering

COMMITTEE MEMBER: Martin Koch, Lecturer and Technician in Industrial-Manufacturing Engineering Department 


\section{ABSTRACT \\ SLM 125 Single Track and Density Cube Characterization for 316L Stainless Steel Cullen Goss}

Selective Laser Melting is a rapidly developing additive manufacturing technique that can be used to create unique metal parts with tailormade properties not possible using traditional manufacturing. To understand the process from a most basic level, this study investigates system capabilities when melting single tracks of material. Individual tracks allow for a wide range of scan speeds and laser powers to be utilized and the melt pools analyzed. I discuss how existing studies and simulations can be used to narrow down the selection of potentially successful parameter combinations as well as the limitations of interpretation for single track information. Once we attain a solid understanding of what parameters perform well at a bead level, we can move onto looking at complete 3D parts. A challenge we have faced is creating near fully dense parts and determining a reliable density measurement technique that is accessible for operators at our university. Our results show that the previously determined optimized scan speed and laser power can consistently create parts with $>99.5 \%$ density over a range of sizes using an analysis method utilizing readily available equipment and software. 


\section{ACKNOWLEDGMENTS}

First, I would like to thank my advisor throughout the year, Dr. Wang. I had a lot of uncertainty going into my master's program and did not know exactly where to focus and you helped guide me through the numerous obstacles that I encountered throughout this process.

I would also like to thank Lawrence Livermore National Labs for providing the machine that made this experiment possible. This entire learning experience was made unique through their desire to increase the field of knowledge surrounding selective laser melting.

Finally, I would like to thank the machine operator, Hajime Yamanaka, because he was so much more than just the machine operator. He took time out of his busy schedule to help trouble shoot problems throughout the process. He also helped me time and time again with microscopy and metallography as I was first learning to use the different instruments and techniques. 


\section{TABLE OF CONTENTS}

List of Tables viii

List of Figures ix

\section{Chapter}

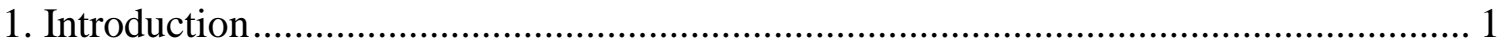

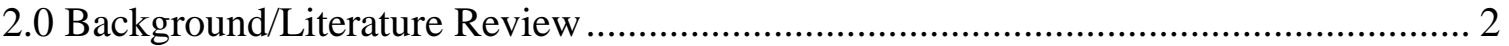

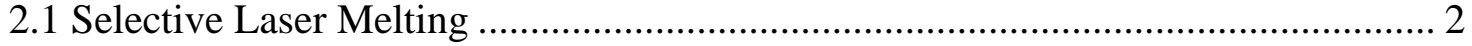

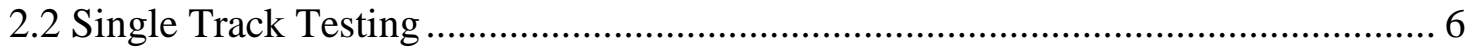

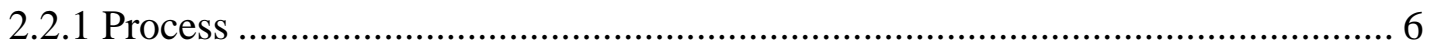

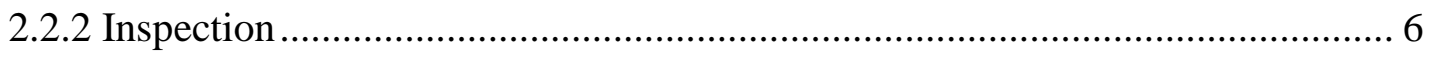

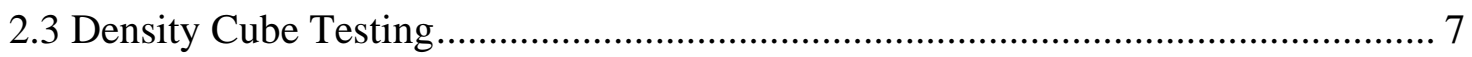

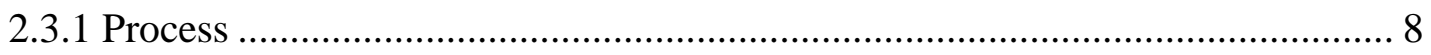

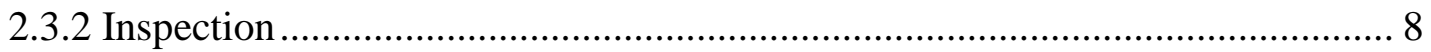

3.0 Single track Experiment ...................................................................................... 11

$3.1 \mathrm{DOE}$

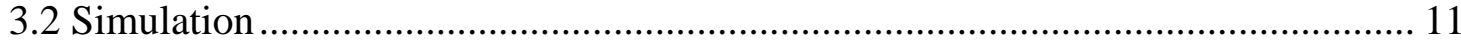

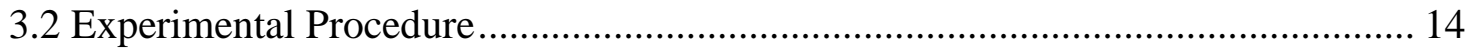

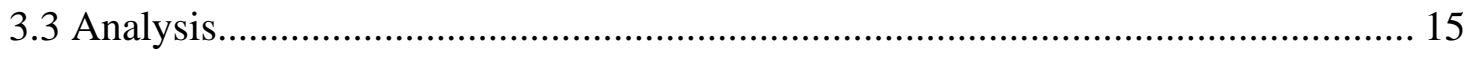

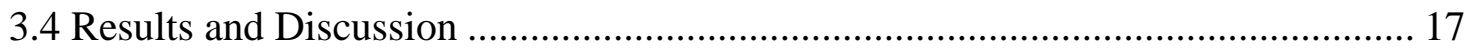

4.0 Density Cube Experiment …………………………...................................... 24

4.1 Experimental Procedure ................................................................................. 24

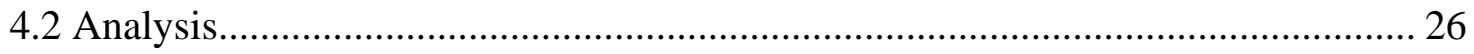

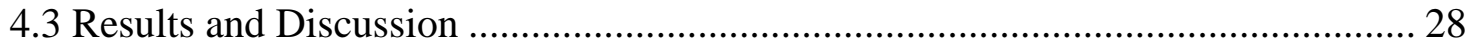




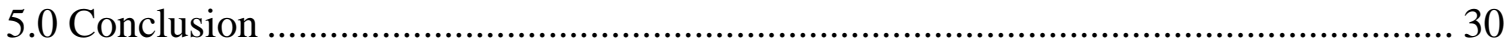

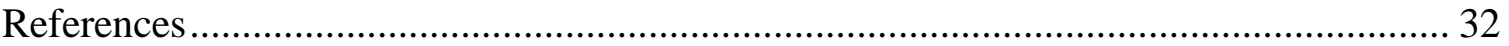

Appendices

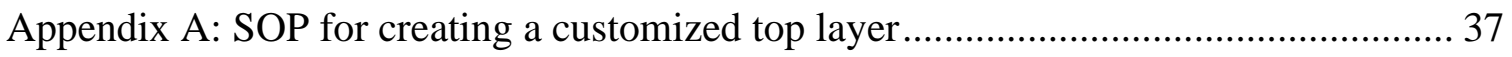

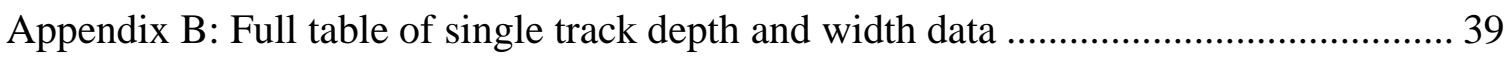




\section{LIST OF TABLES}

Table

Page

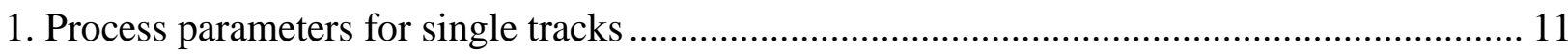

2. Description of variables in Eagar-Tsai Model ......................................................... 12

3. Comparison of theoretical melt pools with emphasis on equal linear energy densities,

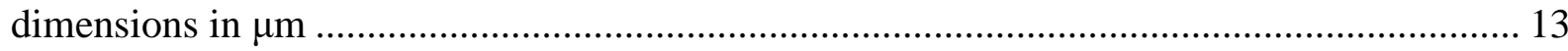

4. Micro-Vu images taken at $273 \mathrm{x}$ magnification of top surface of single tracks..................... 18 


\section{LIST OF FIGURES}

Figure

1. SLM 125 machine on Cal Poly campus donated by Lawrence Livermore National

Labs. Image courtesy of Dr. Xuan Wang ....................................................................... 3

2. Basic SLM Schematic (Brandt, Easton, and Sun, 2016) .................................................. 4

3. Gas atomization of metal powders. Image courtesy of LPW Technology............................ 5

4. 316L stainless steel metal powder created by gas atomization captured by SEM

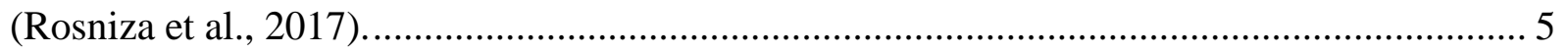

5. Example of SEM images of single tracks created by EOS M270 system with Alloy

IN625 (Dilip et al., 2016) .......................................................................................... 7

6. Archimedes method testing apparatus (Spierings, Schneider, and Eggenberger, 2011).......... 9

7. Example of capabilities of x-ray scanning to analyze porosity within a metal part

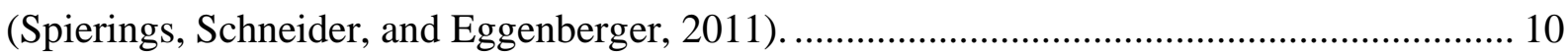

8. (a) Theoretical melt pool depths for test print parameters. (b) Theoretical melt pool

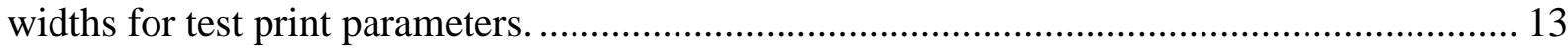

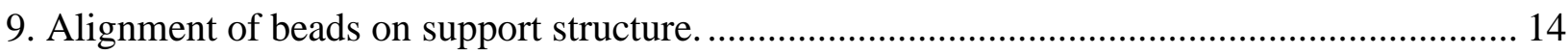

10. Organization of single track blocks on build plate ...................................................... 15

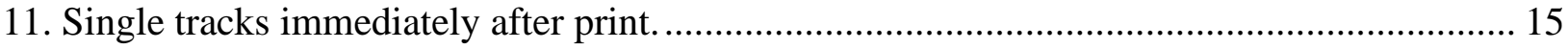

12. Single track $100 \mathrm{~W}$ x $600 \mathrm{~mm} / \mathrm{s}$ on top of checkerboard pattern support........................... 16

13. (a) $150 \mathrm{~W} \times 1000 \mathrm{~mm} / \mathrm{s}$ melt pool at $100 \mathrm{x}$ magnification. (b) $300 \mathrm{~W} \times 1000 \mathrm{~mm} / \mathrm{s}$ melt

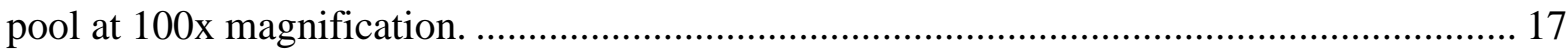

14. (a) $150 \mathrm{~W} \times 400 \mathrm{~mm} / \mathrm{s}$ bead at $273 \mathrm{x}$ magnification. (b) $250 \mathrm{~W} \times 400 \mathrm{~mm} / \mathrm{s}$ bead at $273 \mathrm{x}$ magnification.

15. Single track bead widths measured with Micro-Vu showing general positive relationship with LED; red points represent the $250 \mathrm{~W}$ tracks........................................ 20

16. Reference drawing for locations of width and depth measurements on melt pool............... 20

17. Comparison of theoretical and experimental melt pool width with the experimental being consistently wider.

18. Comparison of theoretical and experimental melt pool depth with experimental results consistently higher. 
19. Visualization of differences in width between experimental and theoretical data.

20. Visualization of differences in depth between experimental and theoretical data. 22

21. Relative density of $8 \times 8 \times 8 \mathrm{~mm}$ cubes taken with micrometer and digital scale (Pohl, 2019). 24

22. Netfabb simulation of 30x30x30mm density sample with warpage around bottom 25

23. Warpage of 30x30x30mm density cube sample. 26

24. Small density samples with porosity defect in lower portion.

25. Micrograph from $12 \mathrm{~mm}$ sample with raised threshold that includes scratch running from top right to bottom left. 28

26. Relative density with $95 \%$ confidence intervals using micrograph analysis. 


\section{INTRODUCTION}

The use of metals in additive manufacturing has seen significant growth and development in recent years in both the research and industrial domains. This manufacturing method holds great potential in the automotive, aerospace, and consumer product markets if processes can be honed and tuned to provide clear advantages over net shape and material removal processes. The main advantage is the ability to rapidly prototype and even manufacture parts at an industrial scale to avoid costly molds and long lead times (Kruth et al., 2005). This advantage only remains when the success rates of builds are high.

One specific facet of additive manufacturing is Selective Laser Melting (SLM) which creates metallic parts through powder bed fusion. This is one of many metal 3D printing techniques and appears to hold promise for creating near finished good quality components (An Overview of the Most Common Types of Metal 3D Printing). In recent years, developments have been made in all areas surrounding SLM such as modeling, post processing, and standard development to name a few (Liu et al.,2018 and Laakso et al., 2016). However, to see SLM grow into a more effective manufacturing technique will require further investment in the surrounding knowledge base as the overall equipment efficiencies are still well below world class standards across industries.

This thesis aims to categorize the behavior of the SLM 125 machine at two of the most basic print tests, a single track (also called a bead test) and density cube prints. The idea of the single track test is to examine how laser power and scan speed affect individual beads created by the laser on a single pass. The density cubes are used to evaluate print parameters as layers are stacked into a cube (Badrosamay et al., 2009).

This document begins with background information detailing the selective laser melting process and existing strategies for the tests being conducted. In addition, basic modeling techniques will be covered. The next section will be composed of a summary of the problem statement with clear objectives for the results. The experimental procedure and initial results will follow the objectives. Finally, a discussion of the results with learnings from both procedures will be discussed and lead into what further improvements could be made in future studies. 


\subsection{BACKGROUND/LITERATURE REVIEW}

Many technologies capable of producing 3D printed metal parts have been developed and improved upon in the last 5 years. The focus of this research will be on Selective Laser Melting (SLM) (An Overview of the Most Common Types of Metal 3D Printing). SLM process involves layering metal powder and using a high power laser to melt and micro-

weld the particles to each other in the desired pattern. This process can take from hours to weeks depending on the complexity and size of the structure being created, so a failure anywhere in the build time can lead to days of wasted time in addition to material and build plate waste. Reducing the probability of a failure gives SLM an advantage over other manufacturing processes like casting that may require weeks of lead time to create the mold.

\subsection{Selective Laser Melting}

SLM is one of the most popular forms of metal 3D printing with many different companies making use of this method to create their products. The basics of this additive method involve using a CAD file converted to an STL and creating the part in a sequence of two-dimensional slices. For each slice, the machine goes through a similar process. The machine being used for this experiment is the SLM 125 shown in Figure 1. 


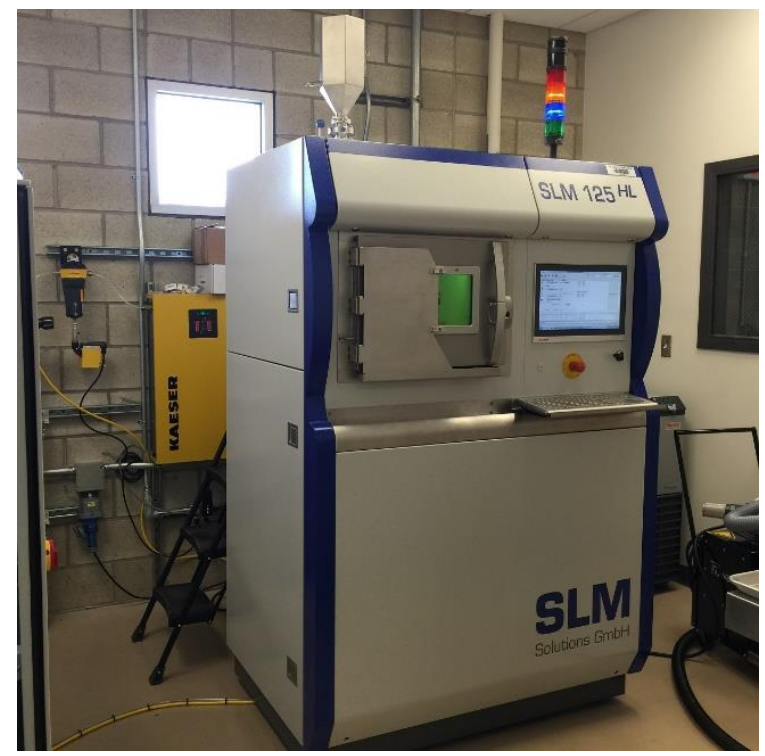

Figure 1. SLM 125 machine on Cal Poly campus donated by Lawrence Livermore National Labs. Image courtesy of Dr. Xuan Wang

The first step is for the to fall into the recoating mechanism which is them spread over the build plate or previous layer. Next, a high power laser (or more commonly, multiple lasers to speed up the process) is used to selectively melt and micro-weld the current layer together. In addition, the laser will also melt some of the previous layer to ensure the layers bond to each other (Dilip et al., 2017). Finally, the build platform is lowered, and the process is repeated until the part or parts are complete. Throughout the process, argon is flowing across the build plate to create an inert environment so no oxides will form. The process is illustrated in Figure 2 below. 


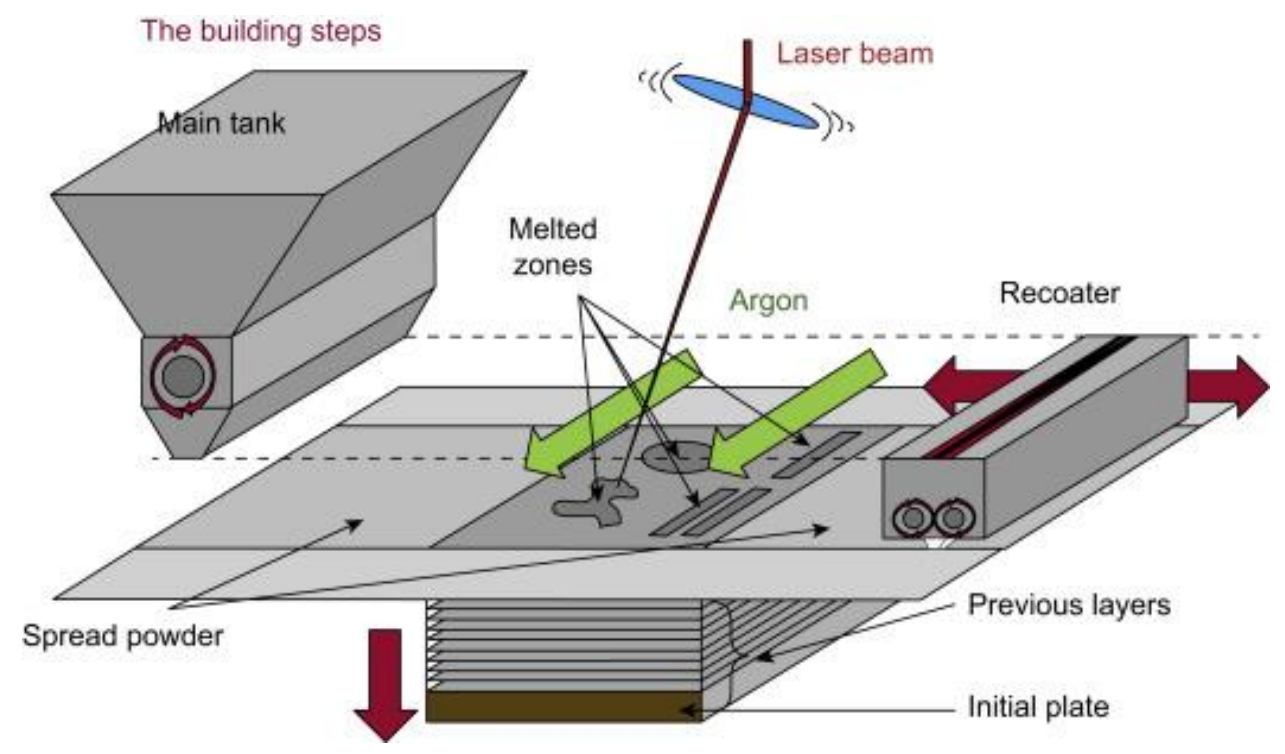

Figure 2: Basic SLM Schematic (Brandt, Easton, and Sun, 2016)

Like other additive manufacturing, the benefits of SLM are its manufacturing flexibility, short lead times, and potential for complex geometries. Another benefit unique to the use of metal is the microstructure and resulting material properties from being heat treated and micro-welded. Parts can be designed to optimize any number of properties including hardness, strength, toughness, or failure mechanism (Uddin et al., 2018 and Han et al., 2017). SLM also lends itself well to certain types of metals that may be difficult to machine such as stainless steel (Yakout, Elbestawi, and Veldhuis, 2019). While the lead time for an individual part may be short, the build time for each part can take days or even weeks.

There are as many as 130 parameters that could affect the sample being printed. Depending on the type of machine and goal for the part, there are any number of combinations to be successful. They range from commonly adjusted parameters such as laser power and scan speed to the atmosphere of the print chamber (Kamath, et al., 2013). For the specific machine being considered for this thesis, SLM 125 by SLM Solutions, many of the parameters are locked and therefore outside the scope of the project. Other parameters such have scan strategy have been narrowed down to either stripes or checkerboard, so we will limit this study to varying laser power and scan speed. Even within those two parameters, we expect to have multiple solutions to successful builds (Monroy et al. 2015). In addition, the metal powder will be 316L stainless steel because 
of its reliability and relative safety compared to other metal powders. The powder used was created through gas atomization which is depicted in Figure 3.

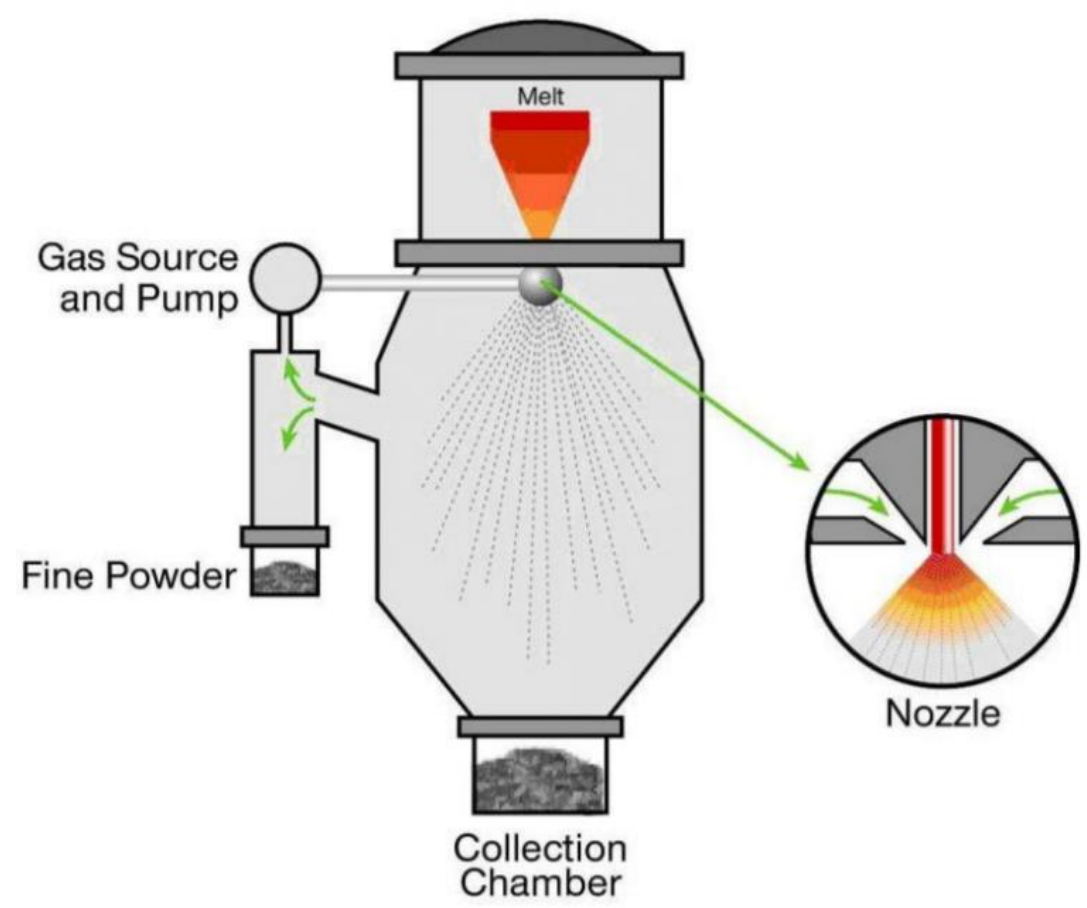

Figure 3. Gas atomization of metal powders. Image courtesy of LPW Technology. The bulk material is first melted and pushed through a nozzle. As soon as the material exits the nozzle, it is blasted by air which causes the molten material to cool into mostly spherical pellets shown in Figure 4.

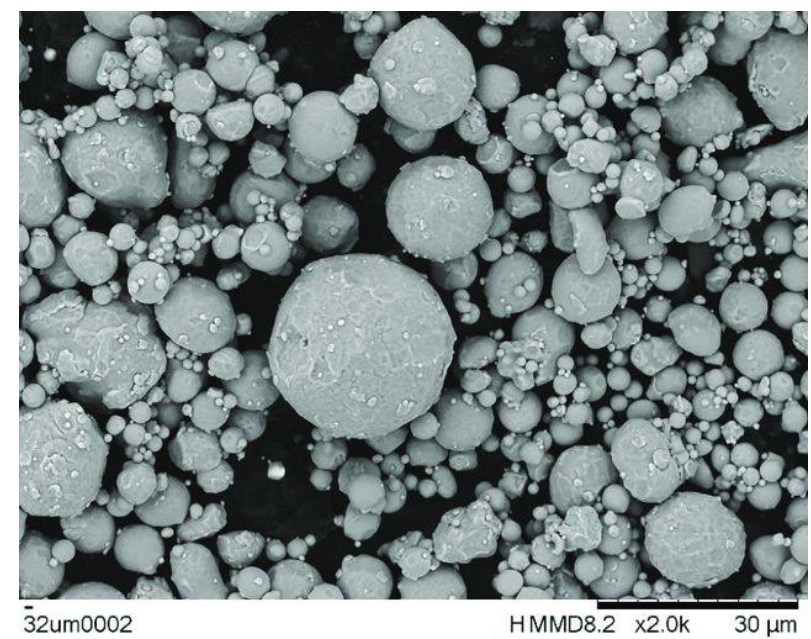

Figure 4. 316L stainless steel metal powder created by gas atomization captured by SEM (Rosniza et al., 2017). 


\subsection{Single Track Testing}

Single track testing, also known as bead testing, is preformed to analyze the bead created by the machine at various process parameters. The use of individual tracks that are spread out enough that they do not affect each other allows for the bead quality and geometry to be examined independently of interactions with other tracks.

\subsubsection{Process}

This test can be performed directly on the build plate or on a support structure with a flat surface printed on the top layer for the tracks to be laid on. Because the beads can be printed so quickly, the entire usable range of machine parameters can be tested quickly. Often, a single track experiment will span the entire range of laser powers and scan speeds to find the optimal operating parameters.

For this process, we will assume the more complicated scenario of using supports rather than printing directly onto a build plate. The operation begins with deciding how to organize the supports on the build plate and the lengths of the tracks (typically 10$40 \mathrm{~mm})$. Next, the single tracks must be printed.

The SLM machine does not normally print the single track geometry as a single line in a design software will cause the laser to scan back and forth. However, two common alternatives exist to "trick" the machine into scanning single tracks. First, support structure naturally prints as a single vector, so custom support parameters may be created and then applied on top, rather than underneath, of the main support structure. The alternative is to manually edit the code used to direct the laser for the top layer. SLM Solutions has created an in depth description on how to properly create any sort of custom layer in this manner (Grylls, 2018). Appendix 1 shows step by step how this can be accomplished.

\subsubsection{Inspection}

The primary forms of analysis for a single track are visual inspection for track defects such as balling or discontinuities followed by measurement of the track depth and width 
using an optical microscope, SEM, or metrology device such as a Micro-Vu. The resulting images should show a clear transition in track quality from low energy to high energy similar to Figure 5.

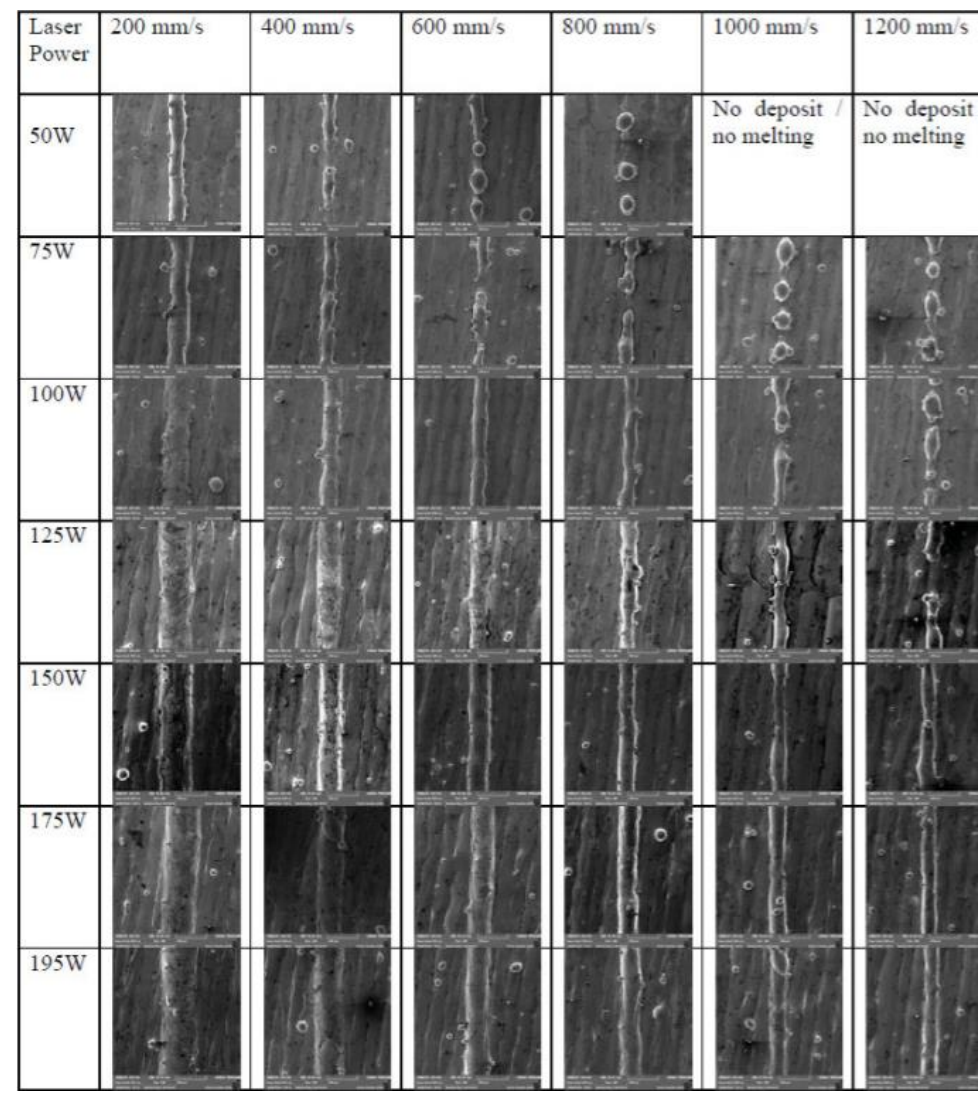

Figure 5. Example of SEM images of single tracks created by EOS M270 system with Alloy IN625 (Dilip et al., 2016)

It should be noted that the single track testing does not tell everything about the quality of a print. While an individual bead may print well, it may be difficult to achieve fully dense parts. To further categorize the machine, machine operators may also print density cubes at a range of print parameters that have been narrowed down by the single track test.

\subsection{Density Cube Testing}

Density cubes (or density samples) can provide insightful direction as to what process parameters are ideal for a given situation, especially near totally dense parts. Density cubes are often tested at a variety of laser powers and scan speeds, but factors such as sample dimensions and build strategy also play a role in the success of a build. 


\subsubsection{Process}

Like the single tracks, the first matter of business is to establish what parameters to inspect because changing too many variables can result in confounding effects. In general, studies have found that the highest linear and volumetric energy densities will result in the highest density unless the part is unable to dissipate the greater heat input which is why support structures become increasingly important (Laaks et al., 2016). Density cubes are printed like any other part in the SLM, simply with a support underneath to help with the effects of gravity and heat dissipation. The larger the part, the more important the support becomes, and at some cross section, the heat will not be able to dissipate, and the part will fail.

For this study, we will also vary the size of the cubes. We predict that the larger sized cubes will spread out the distribution the random porosity, thereby resulting in fewer pockets of high or low porosity. This increases the likelihood that our density measurements will be representative of the entire sample

\subsubsection{Inspection}

Density samples are commonly inspected in at least one of four different ways to determine relative density: Archimedes method, x-ray scanning, manual measurement, and micrograph analysis.

The Archimedes method uses the Archimedes principle in which an object when immersed in a fluid will displace the fluid and the fluid will exert a buoyancy force on the object. A typical apparatus for such measurements looks like Figure 6. 


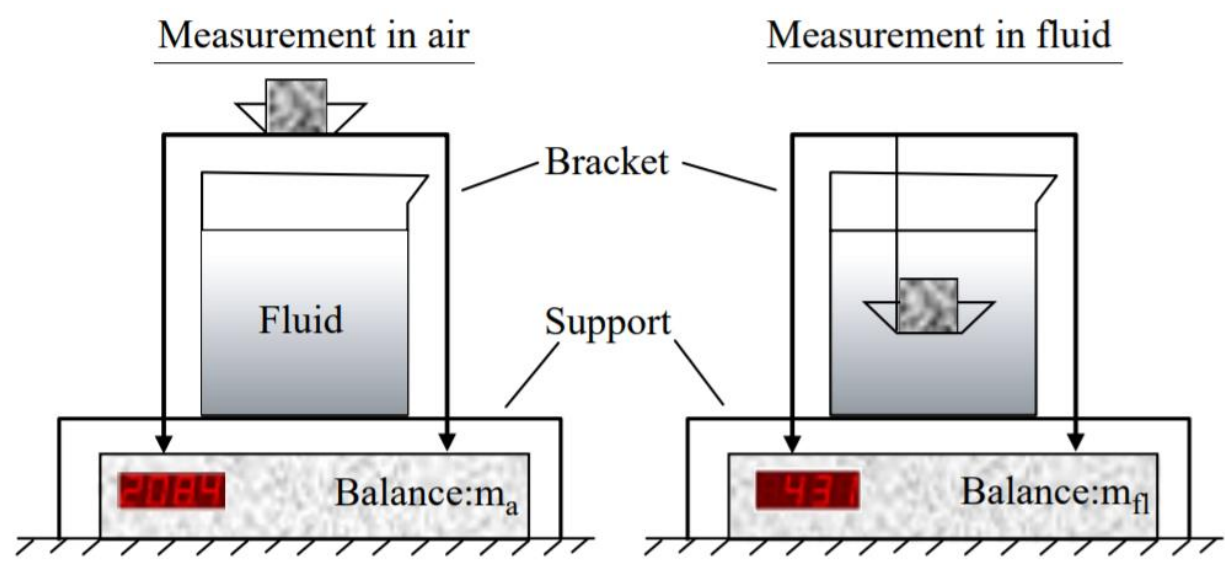

Figure 6. Archimedes method testing apparatus (Spierings, Schneider, and Eggenberger, 2011).

If the difference in mass and change in volume of the fluid can be measured accurately and precisely, then the density of the part can be calculated using the equation 1 .

$$
\rho_{p}=\left(\rho_{f l}-\rho_{a i r}\right) * \frac{m_{a}}{m_{a}-m_{f l}}+\rho_{a i r}
$$

Where $\rho_{\mathrm{fl}}$ is the density of the fluid; $\rho_{\text {air }}$ is the density of air; $m_{\mathrm{a}}$ is the mass of the sample in air, and $m_{\mathrm{fl}}$ is the mass of the sample in fluid. The Archimedes method relies on the fact that the part is totally sealed, otherwise the fluid can seep into internal pores and effect the measurement. This makes low density parts more challenging to measure using this method because they must be sealed, and the mass and density of the sealant must be accounted for in the final calculation (Spierings et al., 2011).

The Archimedes method also has standards associated with it regarding density measurement of powder metallurgy parts ("B 311-93/02," 2002 and "B 962-08," 2008). One of the challenges with many analyses of SLM parts is the lack of standards because the technology is new (National Institute of Standards, 2013). Often, testing methods are borrowed from similar processes.

X-ray scanning requires the most time and most advanced machinery. An X-ray machine scans through individual layers of the part that can be stitched together by dedicated software to create a 3D image of the part (Spierings, Schneider, and Eggenberger, 2011) like those seen in Figure 7. Ideally, this image would do an adequate job of estimating the total porosity. The process requires calibration for both geometry, axis of rotation, and 
full density. Each scan can take well over an hour and equipment can cost easily over $\$ 350,000$ which results in high costs for sending individual samples to be measured.
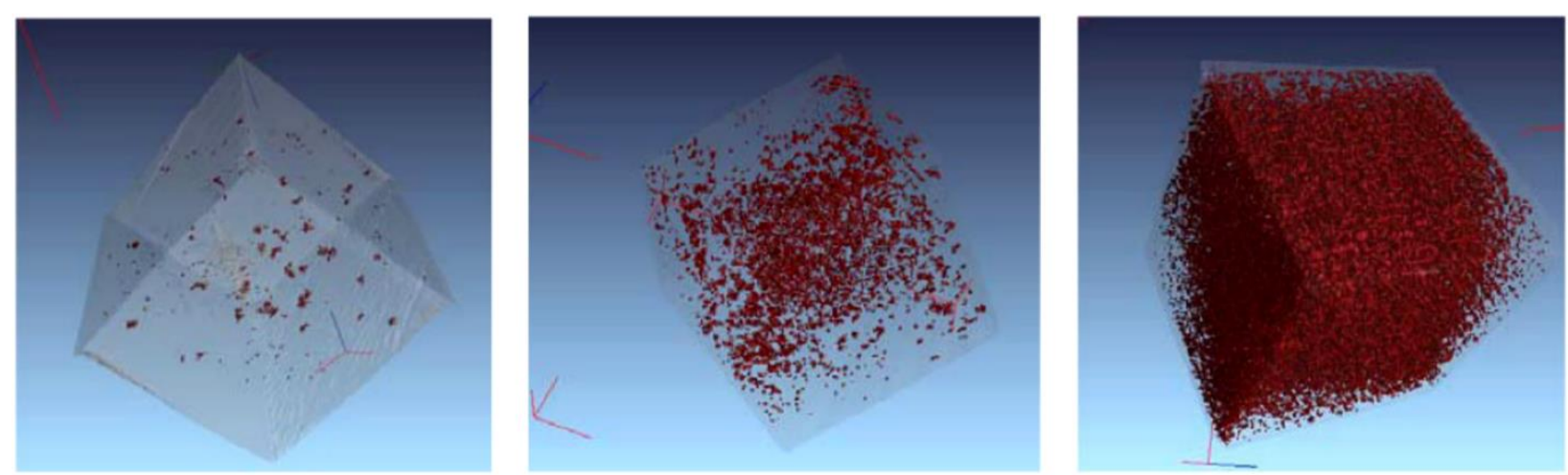

Figure 7. Example of capabilities of $x$-ray scanning to analyze porosity within a metal part (Spierings, Schneider, and Eggenberger, 2011).

Manual measurement is the simplest and least precise of these 4 methods. Manual measurement requires only a scale and a micrometer or caliber to measure side lengths. One simply calculates the density of the part using equation 2 .

$$
\rho_{p}=\frac{m}{l * w * h}
$$

Where $m$ is mass in grams, $l$ is length in millimeters, $w$ is width in millimeters, and $h$ is height in millimeters. This method can be completed quickly and inexpensively; however, the results can vary multiple percent depending on where the measurements are taken.

Micrograph analysis is a destructive method of testing the density that requires cutting the sample to expose either a vertical or horizontal cross section or cross sections. The sample is then imaged under a microscope and micrographs are taken at each cross section. For high density parts, the level of magnification is not crucial in determining the level of porosity (Spierings, Schneider, and Eggenberger, 2011). The micrographs are then analyzed with an image processor that can differentiate based on the differing contrast of material and voids. The area percentage of voids can then be extrapolated to a volume (Ihsani and Ihsani). The largest concern with this method is that the cross section examined may not be representative of the entire sample. 


\subsection{SINGLE TRACK EXPERIMENT}

The objective of the two experiments in this thesis aim primarily to better the educational understanding of the optimal process parameters and test methods for high density prints.

\subsection{DOE}

The idea of the single track experiment is to examine a wide range of feasible process parameters (Zhang et al., 2018). Table 1 below shows the range of scan speeds and laser powers being tested. They were designed around the current operating conditions of $150 \mathrm{~W}$ and $1000 \mathrm{~mm} / \mathrm{s}$.

Table 1. Process parameters for single tracks

\begin{tabular}{|c|c|c|c|c|c|c|c|}
\hline Power (W) & \multicolumn{7}{|c|}{ Scan Speed (mm/s) } \\
\hline 50 & 400 & 600 & 800 & 1000 & 1200 & 1400 & 1600 \\
\hline 100 & 400 & 600 & 800 & 1000 & 1200 & 1400 & 1600 \\
\hline 150 & 400 & 600 & 800 & 1000 & 1200 & 1400 & 1600 \\
\hline 200 & 400 & 600 & 800 & 1000 & 1200 & 1400 & 1600 \\
\hline 250 & 400 & 600 & 800 & 1000 & 1200 & 1400 & 1600 \\
\hline 300 & 400 & 600 & 800 & 1000 & 1200 & 1400 & 1600 \\
\hline
\end{tabular}

It is not expected to create unblemished tracks at each of the scan speeds, but comparisons of equivalent linear energy densities, e.g. $50 \mathrm{~W}$ at $400 \mathrm{~mm} / \mathrm{s}$ and $100 \mathrm{~W}$ at 800 $\mathrm{mm} / \mathrm{s}$, could yield interesting insight into potential for multiple optimal settings for the machine when targeting fully dense parts. Unless otherwise stated, layer thickness equals $30 \mu \mathrm{m}$, spot size equals $70 \mu$ and hatching distance equals $120 \mu \mathrm{m}$. Additionally, the chamber and build plate were preheated to $150^{\circ} \mathrm{C}$ to reduce the risk of balling ( $\mathrm{Gu}$ and Shen, 2007).

\subsection{Simulation}

There are two primary theoretical welding models that have been used with some degree of success to model the melt pool of a single track pass, the Rosenthal model and the Eagar-Tsai model (Lecoanet et al. 2014). The SLM process behaves similarly to that of a 
welding arc moving over a semi-infinite flat plate, just at a much smaller scale. The only difference between these two models is the assumption of a point heat source for the former versus that of a gaussian heat source (more realistic for a laser) for the latter (Eagar and Tsai, 1983 and Eagar and Tsai 1984). Because of the relatively short computation time, I proceeded with the Eagar-Tsai model shown in equation 3.

$$
T-T_{o}=\int_{0}^{t} d t^{\prime \prime} \frac{q}{\pi \rho c(4 \pi a)^{\frac{1}{2}}} \frac{t^{\prime \prime-\frac{1}{2}}}{2 a t^{\prime \prime}+\sigma^{2}} e^{-\frac{w^{2}+y^{2}+2 w v t^{\prime \prime}+v^{2} t^{\prime \prime 2}}{4 a t^{\prime \prime}+2 \sigma^{2}}-\frac{z^{2}}{4 a t^{\prime \prime}}}
$$

Table 2. Description of variables in Eagar-Tsai Model

\begin{tabular}{|c|c|}
\hline $\mathrm{a}$ & Thermal diffusivity \\
\hline $\mathrm{c}$ & Specific heat \\
\hline $\mathrm{q}$ & Power \\
\hline $\mathrm{T}$ & Temperature \\
\hline $\mathrm{T}_{\mathrm{o}}$ & Initial temperature \\
\hline $\mathrm{V}$ & Scan speed \\
\hline $\mathrm{W}$ & Distance in $\mathrm{x}$ direction of speed $\mathrm{v}(\mathrm{w}=\mathrm{x}-$ \\
& Distance in $\mathrm{y}$ direction \\
\hline $\mathrm{y}$ & Distance in $\mathrm{z}$ direction \\
\hline $\mathrm{z}$ & Distribution parameter \\
\hline$\sigma$ & density \\
\hline$\rho$ & $\mathrm{t}-\mathrm{t}^{\prime}$ \\
\hline $\mathrm{t}^{\prime}$ & \\
\hline
\end{tabular}

Both solutions ignore many other significant effects including convection/radiative cooling on the surface, fluctuating thermal properties with temperature, differences in properties for powder

versus bulk material, and finite plate size. One other assumption explored in a study by Cheng and Chou tested the effect of residual heat from the source that does not immediately disappear when the heat source has moved on (Cheng and Chou, 2015). Figure 8 below shows how melt pool widths and depths vary as a function of linear energy density (laser power/scan speed) according to the Eagar-Tsai model. 

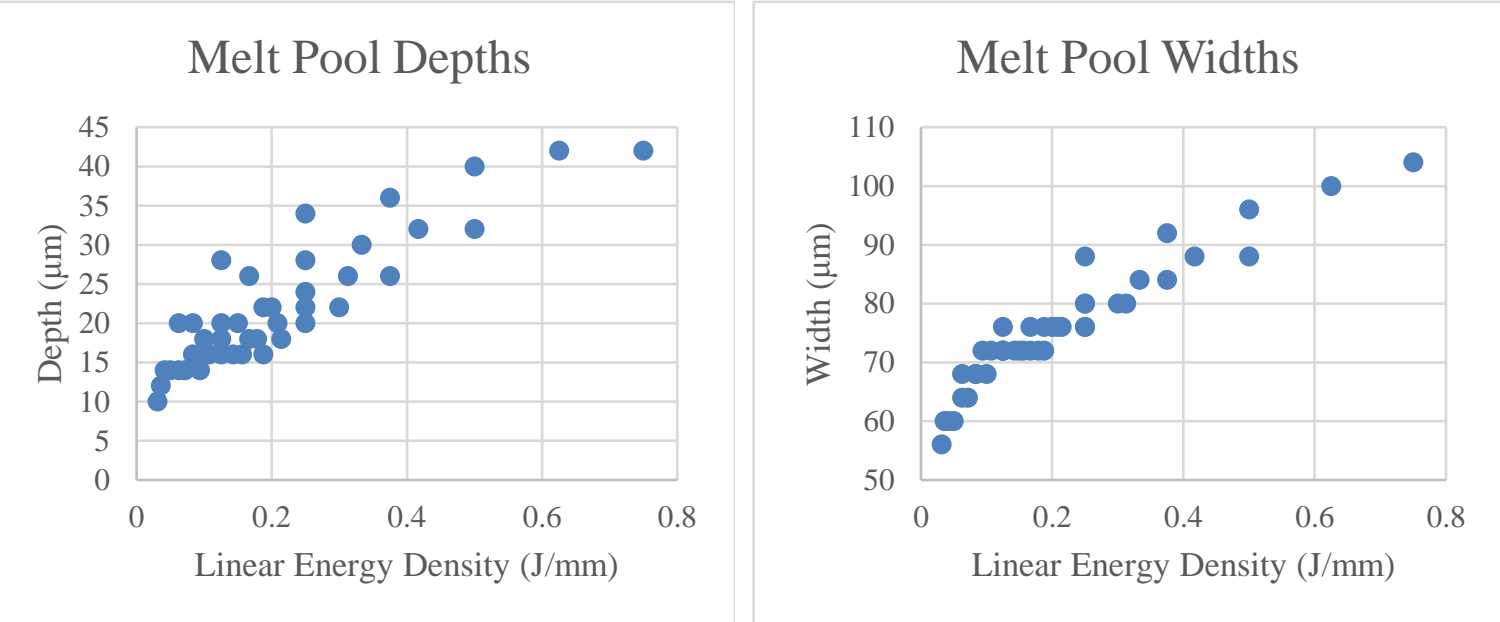

Figure 8. (a) Theoretical melt pool depths for test print parameters. (b) Theoretical melt pool widths for test print parameters.

The combination of scan speeds and laser powers created some overlap of LEDs. At these overlaps, the deeper and wider melt pool is created by the combination with the lower speed and higher power, as shown in Table 2. The highlighted values correspond to prints with equal LED. This will be an interesting effect to check for in the prints.

Table 3. Comparison of theoretical melt pools with emphasis on equal linear energy densities, dimensions in $\mu \mathrm{m}$

\begin{tabular}{|c|c|c|c|c|c|c|c|}
\hline & \multicolumn{7}{|c|}{ Laser Power (W) } \\
\hline \multirow{8}{*}{ 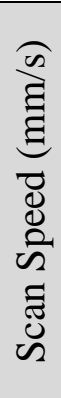 } & & 50 & 100 & 150 & 200 & 250 & 300 \\
\hline & 400 & $76 \times 28$ & $88 \times 34$ & $92 \times 36$ & $96 \times 40$ & $100 \times 42$ & $104 \times 42$ \\
\hline & 600 & $68 \times 20$ & $76 \times 26$ & $80 \times 28$ & $84 \times 30$ & $88 \times 32$ & $88 \times 32$ \\
\hline & 800 & $68 \times 20$ & $72 \times 20$ & $76 \times 22$ & $80 \times 24$ & $80 \times 26$ & $84 \times 26$ \\
\hline & 1000 & $60 \times 14$ & $68 \times 18$ & $72 \times 20$ & $76 \times 22$ & $76 \times 22$ & $80 \times 22$ \\
\hline & 1200 & $60 \times 14$ & $68 \times 16$ & $72 \times 18$ & $72 \times 18$ & $76 \times 20$ & $76 \times 20$ \\
\hline & 1400 & $60 \times 12$ & $64 \times 14$ & $68 \times 16$ & $72 \times 16$ & $72 \times 18$ & $76 \times 18$ \\
\hline & 1600 & $56 \times 10$ & $64 \times 14$ & $68 \times 14$ & $72 \times 16$ & $72 \times 16$ & $72 \times 16$ \\
\hline
\end{tabular}

The phenomena can be traced back to the quadratic influence of the velocity term while the power only contributes linearly (Eagar and Tsai, 1983). Both predictions can be used to choose additional system parameters. Melt pool width gives insight into how far apart beads can be printed (hatching distance) and still melt together to create a solid surface (Perevoshchikova et al., 2017). The larger the hatching distance, the fewer scans need to be made and the less time a print will take. To create a smooth surface and therefore a dense part, the overlap should be close to $30 \%$ (Di et al., 2012). Melt pool depth can be 
used to predict appropriate layer thickness. For layers to stick together and create a fully dense part, the layer needs to penetrate more than 1 layer thick. This will melt the new layer to the previous (Yadroitsev et al., 2012).

All of the weld pools are shown to be far wider than they are deep. This occurs mainly due to the assumption of bulk material properties. Realistically, we expect to see more elongated pools penetrating deeper into the material partially because the laser will be able to penetrate through powder more easily than through bulk material (Pohl, 2019).

\subsection{Experimental Procedure}

The tracks were printed on support structures show below so the build plate would not have to be cut to examine the cross section of the tracks. While this saved the build plate, it did cause some issues in examining the tracks that will be discussed later. The supports each contained 7 tracks aligned $1 \mathrm{~mm}$ apart from each other to prevent interaction of heat affected zones as shown in Figure 9 (Doubenskaia et al. 2016).

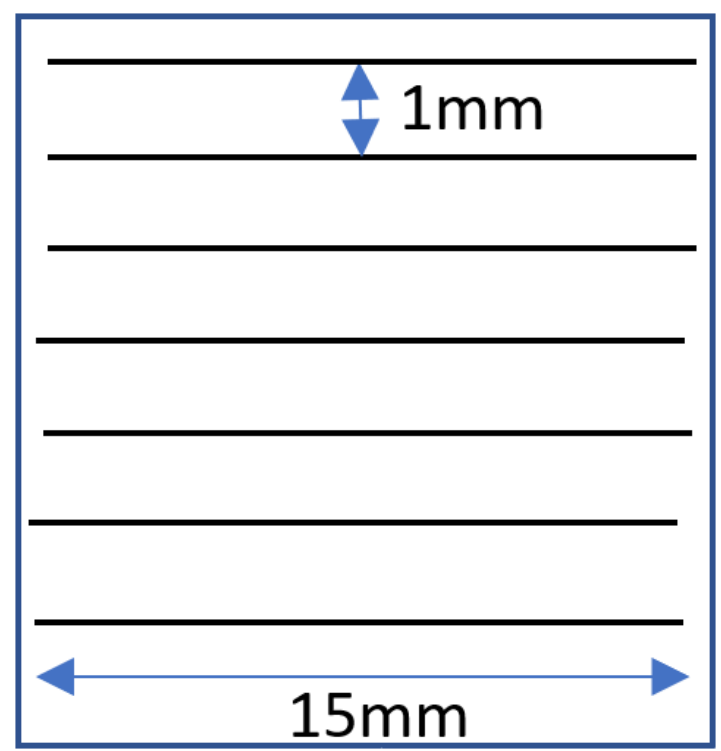

Figure 9. Alignment of beads on support structure.

The supports were then staggered on the build plate to prevent any contamination of one build from another because of air flow. The staggering also ensured that if one part failed and caused damage to the recoater blade, the other parts would not be affected. The layout of the supports can be seen in Figure 10. 


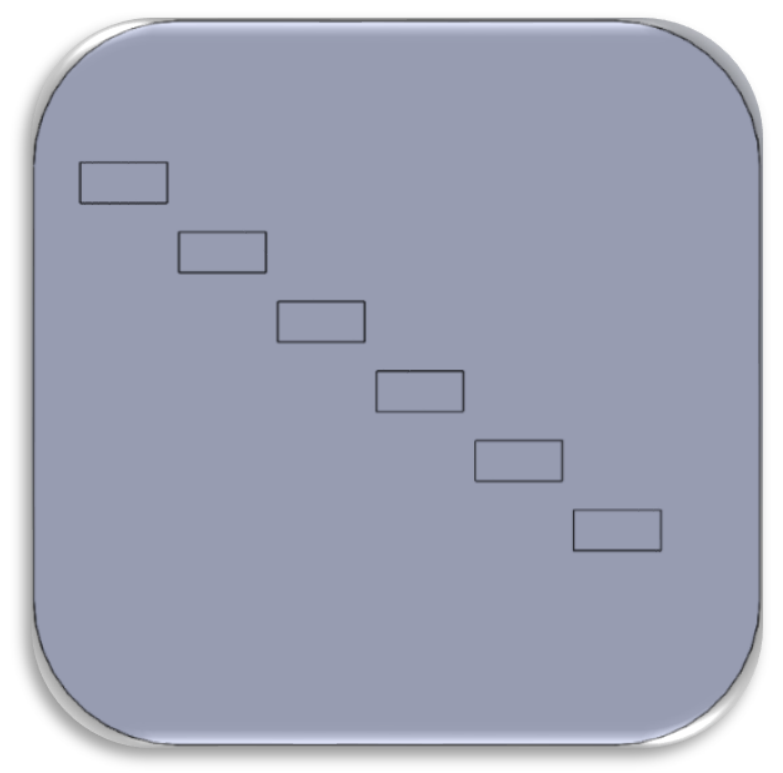

Figure 10. Organization of single track blocks on build plate.

While each of the tracks were printed at unique process parameters, the main structure on which they were printed on was set to the previously determined optimal setting of $150 \mathrm{~W}$ and $1000 \mathrm{~mm} / \mathrm{s}$ (Pohl, 2019). When the parts were initially removed from the machine, it was immediately quite clear which support blocks were associated with which laser power. Figure 11 shows the final prints on the build plate with the highest power closest to the front.

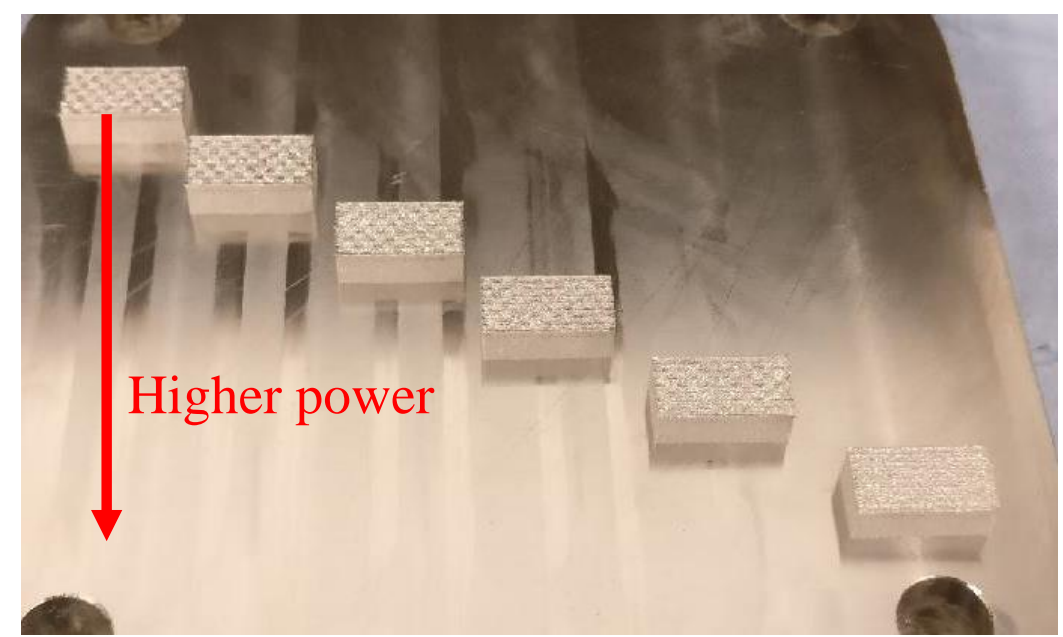

Figure 11. Single tracks immediately after print.

\subsection{Analysis}

To examine the bead characteristics, first a Micro-Vu was used to measure track width, if possible, and quickly sort which combinations of scan speeds and powers could yield 
satisfactory parts. One difficulty in this manner is differentiating the test bead from the beads in the layer below a seen in Figure 12.

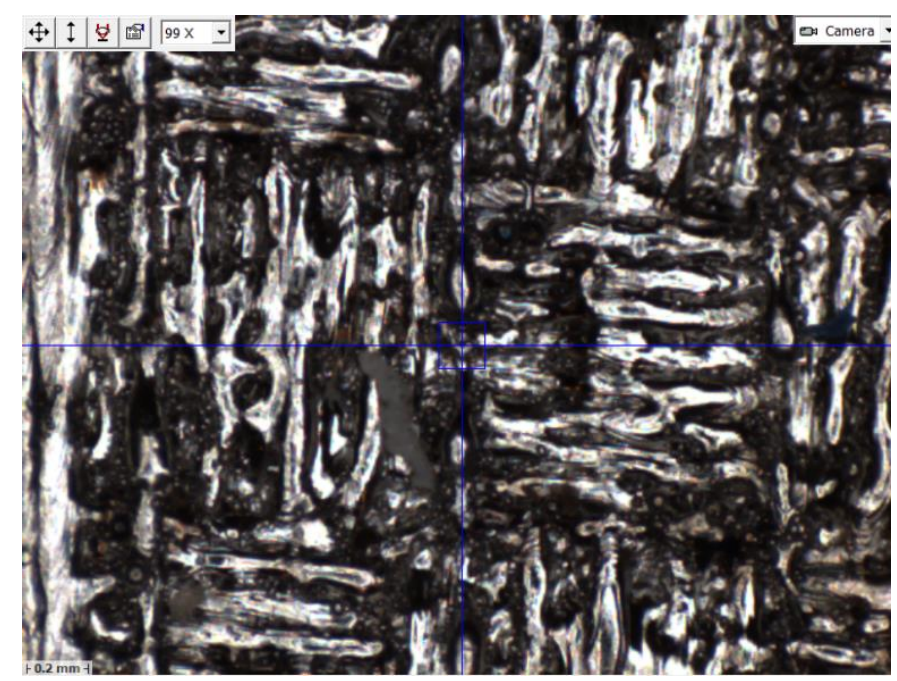

Figure 12. Single track $100 \mathrm{~W}$ x $600 \mathrm{~mm} / \mathrm{s}$ on top of checkerboard pattern support. Applying up-skin, re-melting the top surface, or polishing the final layer of the support block would provide an optically smooth surface for the single track layer (Kaynak and Kitav, 2018). This would cause the beads to stick out starkly against the background; however, the current strategy allows for us to see the way in which beads realistically interact with the layers beneath them (Gong et al., 2016).

Next, the pieces were cut to expose their cross section then polished and etched at $5 \mathrm{~V}$ for 30 seconds with a $10 \%$ by mass oxalic acid solution to expose the microstructure and examine the bead head. Some representative samples are shown below in Figure 13. 


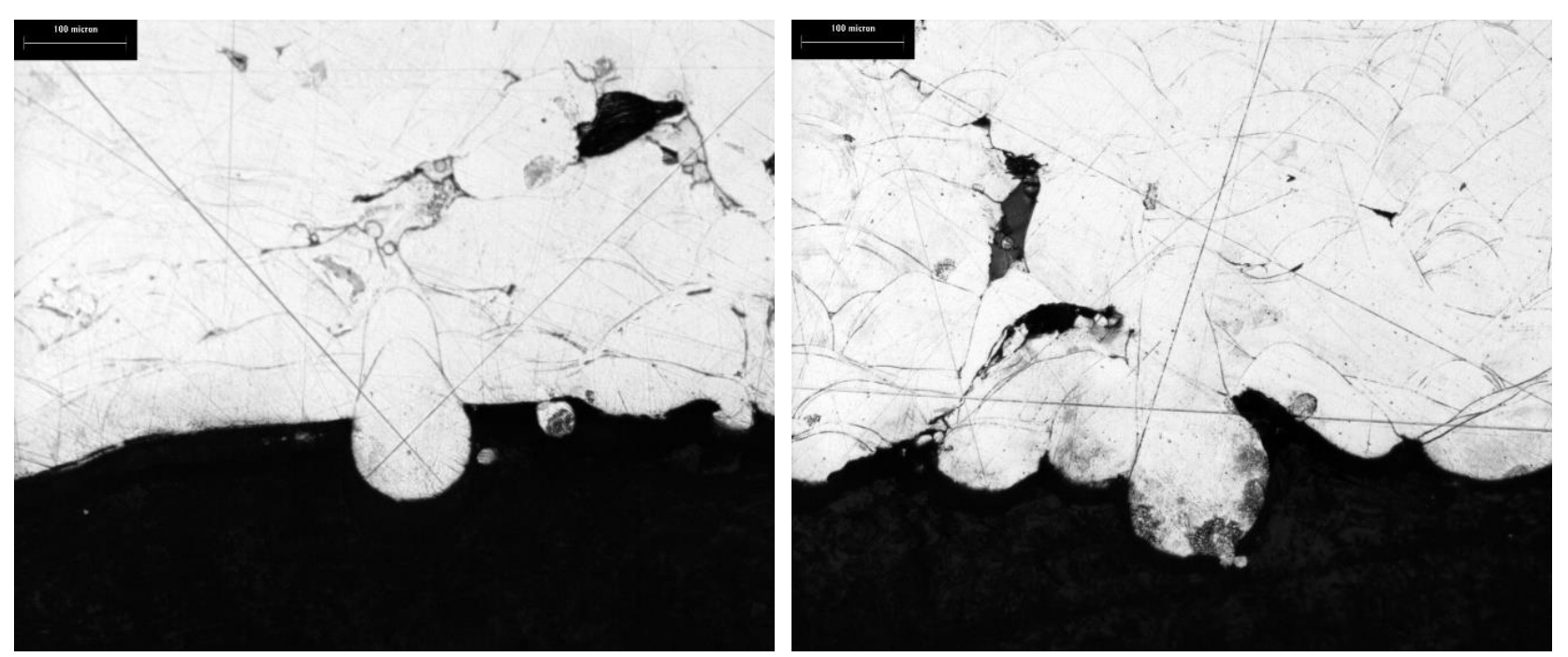

Figure 13. (a) $150 \mathrm{~W} x 1000 \mathrm{~mm} / \mathrm{s}$ melt pool at $100 \mathrm{x}$ magnification. (b) $300 \mathrm{~W} x$ $1000 \mathrm{~mm} / \mathrm{s}$ melt pool at 100x magnification.

\subsection{Results and Discussion}

Immediately, we can see that not all power/speed combinations resulted in clear tracks, all of which are summarized in Table 3. Tracks printed with $150 \mathrm{~W}$ were the first to show somewhat clear tracks at the entire range of speeds. This differs from the Eagar-Tsai model that predicted that some continuous bead would form at each laser power. This result is one drawback of the theoretical model's assumptions. For small variation from the center of the laser, the model predicts unrealistically high temperatures and therefore, some amount of melted material. 
Table 4. Micro-Vu images taken at $273 x$ magnification of top surface of single tracks.

\begin{tabular}{|c|c|c|c|c|c|c|}
\hline & $50 \mathrm{~W}$ & $100 \mathrm{~W}$ & $150 \mathrm{~W}$ & $200 \mathrm{~W}$ & $250 \mathrm{~W}$ & $300 \mathrm{~W}$ \\
\hline $400 \mathrm{~mm} / \mathrm{s}$ & $\begin{array}{l}\text { No visible } \\
\text { track }\end{array}$ & & & & & \\
\hline $600 \mathrm{~mm} / \mathrm{s}$ & $\begin{array}{l}\text { No visible } \\
\text { track }\end{array}$ & & & 2 & & \\
\hline $800 \mathrm{~mm} / \mathrm{s}$ & $\begin{array}{l}\text { No visible } \\
\text { track }\end{array}$ & & & (1) & & \\
\hline $\begin{array}{l}1000 \\
\mathrm{~mm} / \mathrm{s}\end{array}$ & $\begin{array}{l}\text { No visible } \\
\text { track }\end{array}$ & $\begin{array}{l}\text { No visible } \\
\text { track }\end{array}$ & & $\xi$ & & \\
\hline $\begin{array}{l}1200 \\
\mathrm{~mm} / \mathrm{s}\end{array}$ & $\begin{array}{l}\text { No visible } \\
\text { track }\end{array}$ & $\begin{array}{l}\text { No visible } \\
\text { track }\end{array}$ & & & & \\
\hline $\begin{array}{l}1400 \\
\mathrm{~mm} / \mathrm{s}\end{array}$ & $\begin{array}{l}\text { No visible } \\
\text { track }\end{array}$ & $\begin{array}{l}\text { No visible } \\
\text { track }\end{array}$ & & & & \\
\hline $\begin{array}{l}1600 \\
\mathrm{~mm} / \mathrm{s}\end{array}$ & $\begin{array}{l}\text { No visible } \\
\text { track }\end{array}$ & $\begin{array}{l}\text { No visible } \\
\text { track }\end{array}$ & & & & \\
\hline
\end{tabular}

In addition, there appeared to be a stagnation in the development of a continuous bead between $150 \mathrm{~W}$ and $250 \mathrm{~W}$ as seen in Figure 14 below. The model and patterns amongst prints would suggest that the bead thickness would become more prominent with this 
increase in laser power, especially since we see a difference in bead continuity from $250 \mathrm{~W}$ to $300 \mathrm{~W}$.
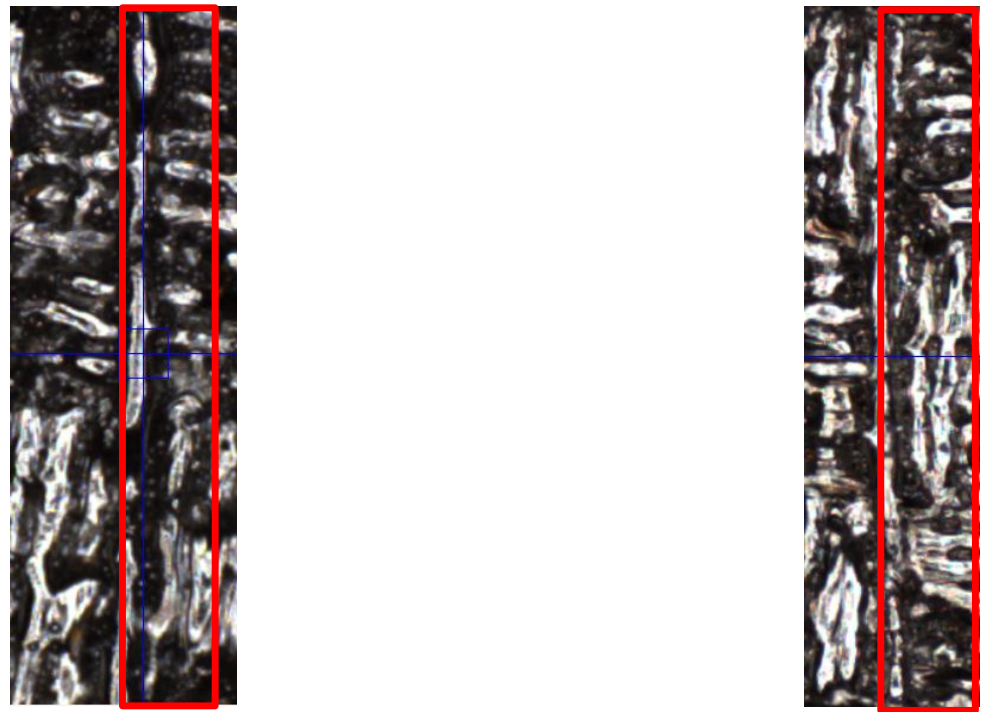

Figure 14. (a) $150 \mathrm{~W} \times 400 \mathrm{~mm} / \mathrm{s}$ bead at $273 \mathrm{x}$ magnification. (b) $250 \mathrm{~W} \times 400 \mathrm{~mm} / \mathrm{s}$ bead at $273 \mathrm{x}$ magnification.

This odd change in track quality is confirmed across the entire range of bead width measurements which is shown in Figure 15. The bead widths as a whole, tend to show a positive correlation with linear energy density; however, the beads created at $250 \mathrm{~W}$ (shown in red) do not follow the same trend as the rest of the data points. For the tracks created at 400,600 , and $800 \mathrm{~mm} / \mathrm{s}$, the bead widths are narrower than tracks at lower linear energy densities. While this is strange behavior, the most likely cause of such tracks has to do with the sampling area and the effects of the layers below. $250 \mathrm{~W}$ is most likely not an innately poor operating point. 


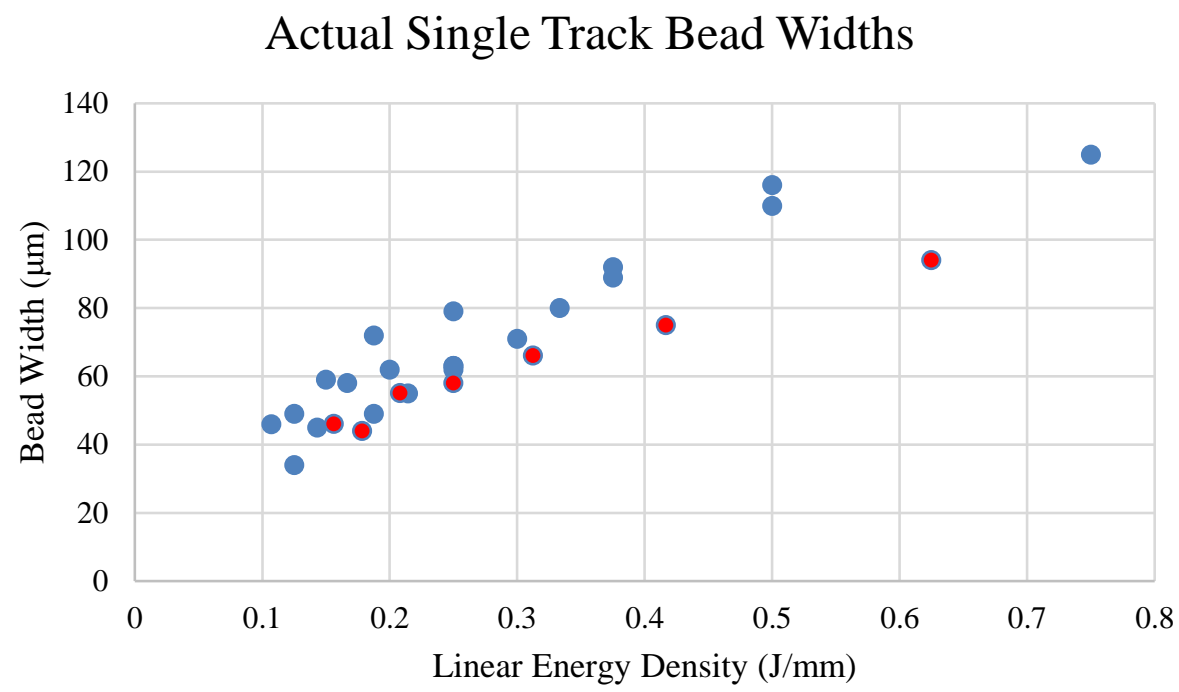

Figure 15. Single track bead widths measured with Micro-Vu showing general positive relationship with LED; red points represent the $250 \mathrm{~W}$ tracks.

While beads are nice because they are the most visible portion of the single track, the melt pools provide more information about how the track is interacting with the rest of the block and can be used to narrow down potential hatch distances and layer thicknesses. Figure 16 illustrates where the widths and depths were measured.

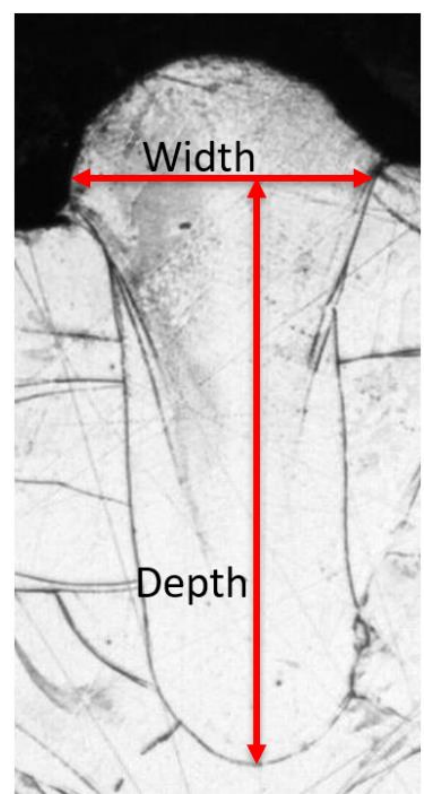

Figure 16. Reference drawing for locations of width and depth measurements on melt pool.

Figures 17 and 18 compare the model melt pool characteristics to the melt pool widths and depths observed under the microscope. Notably, the trends predicted by the model 
remained true while the actual melt pool dimensions differed particularly in the depth. We see a steady increase in depth and width with increasing LED as well as larger melt pools for slow speed/low power at equal LEDs.

Comparison of model and experimental melt pool width

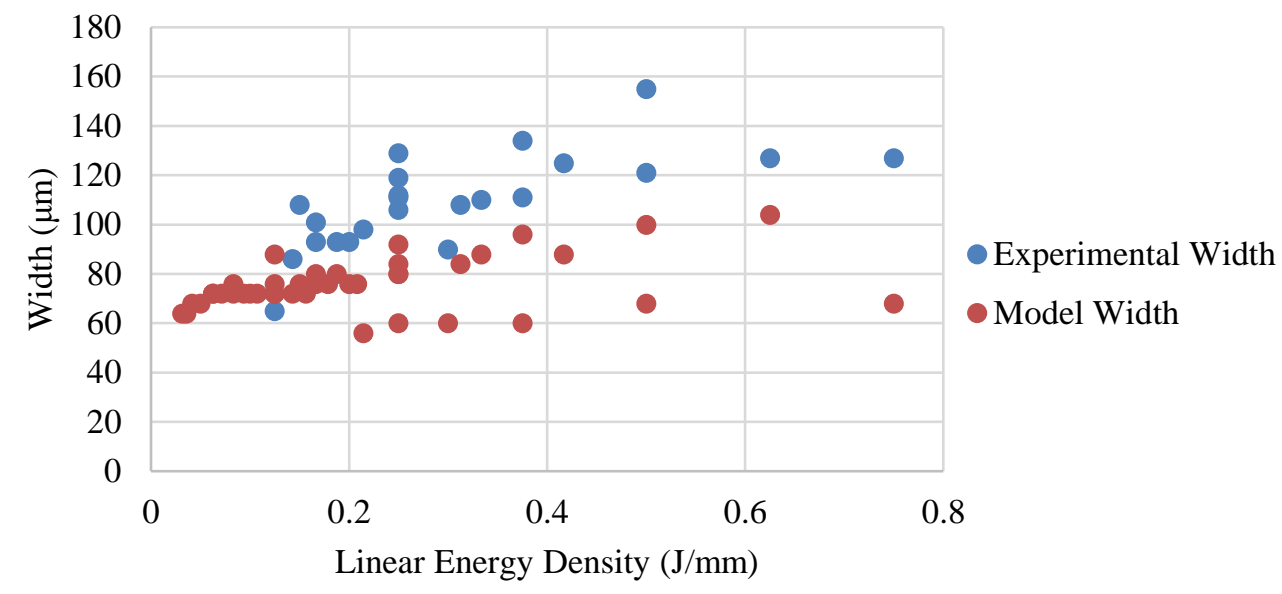

Figure 17. Comparison of theoretical and experimental melt pool width with the experimental being consistently wider.

Comparison of model and experimental melt pool depth

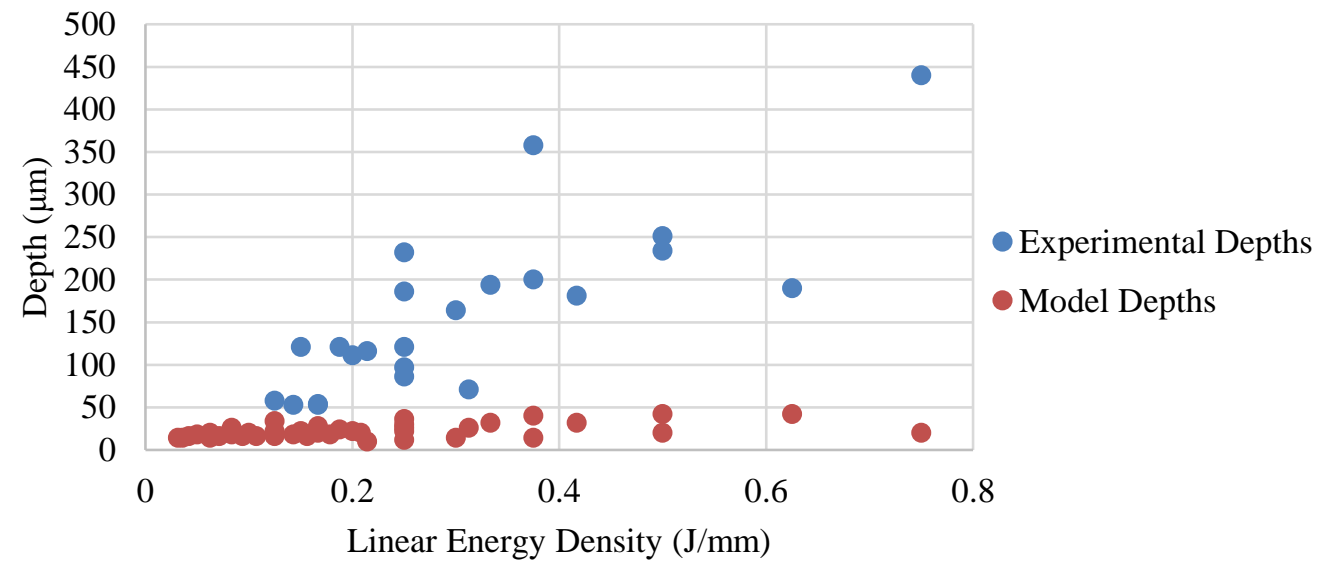

Figure 18. Comparison of theoretical and experimental melt pool depth with experimental results consistently higher.

Another possible way to represent the melt pool geometry, shown in Figures 19 and 20, is by plotting the difference between the experimental and theoretical data which I then 
grouped by scan speed to differentiate samples with the same linear energy density. The data for both shows that the model consistently predicted smaller melt pools.

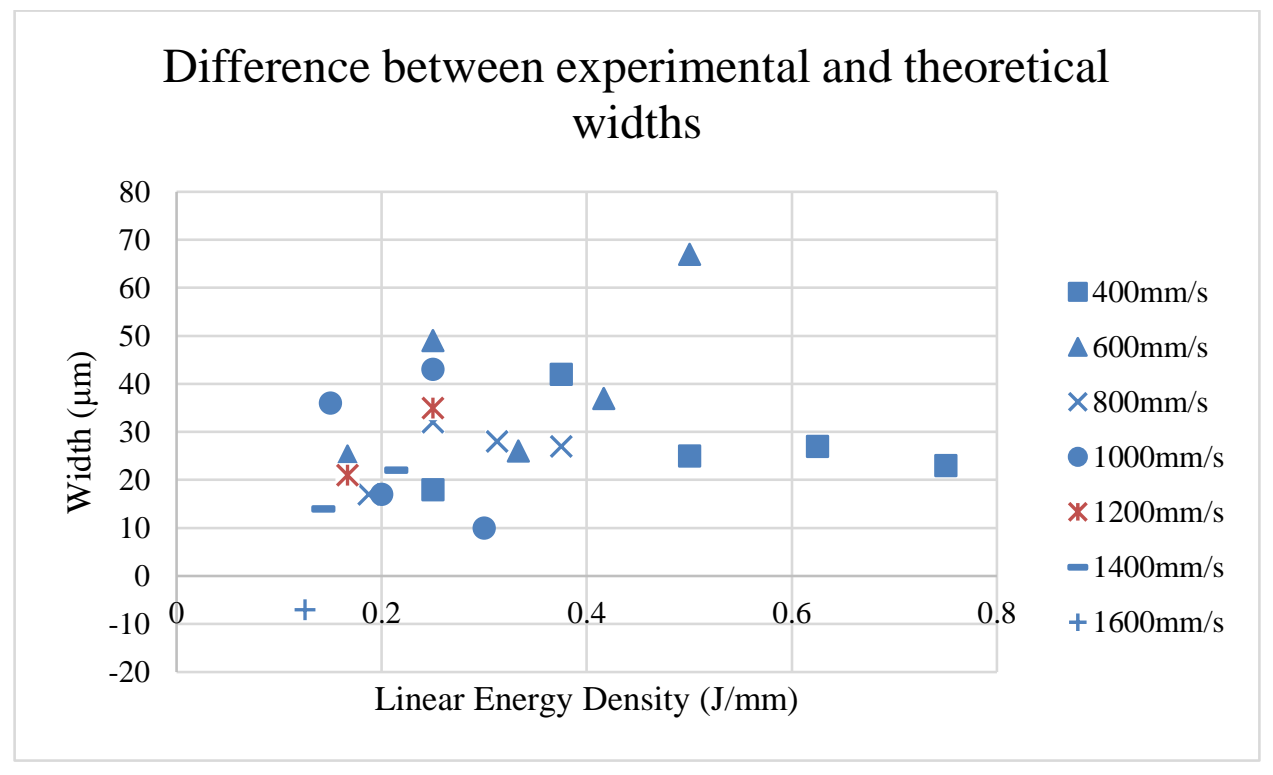

Figure 19. Visualization of differences in width between experimental and theoretical data.

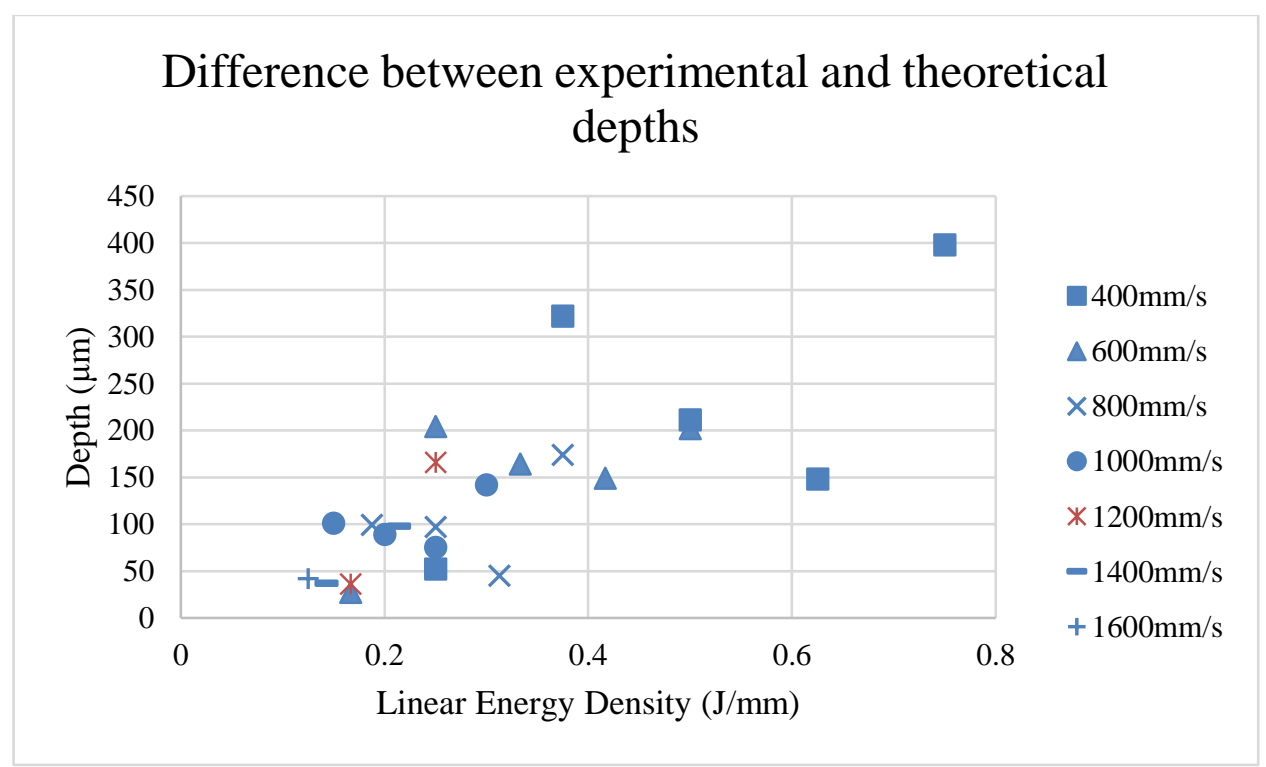

Figure 20. Visualization of differences in depth between experimental and theoretical data.

Using the numerical results tabulated in Appendix B, I ran a stepwise regression model to determine which factors (speed, power, and linear energy density) had significant effect on the widths and depths. However, due to strong correlation between linear energy density and the other two variables $(\mathrm{P}<0.05)$, I redesigned the analysis to only include 
speed, power, and their interaction term. The results of the stepwise analysis showed that both individual variables contributed significantly $(\mathrm{P}<0.05)$ while the interaction did not pass through the stepwise filter of 0.15 . Overall the regressions for both width and depth were significant with $\mathrm{P}=0.000$ although the $\mathrm{R}$-Squared (adjusted) values were $49.99 \%$ and $62.02 \%$ for depth and width respectively. Speed has a negative effect while power has a positive effect which is what we would expect. 


\subsection{DENSITY CUBE EXPERIMENT}

A previous thesis at Cal Poly has already investigated suitable print parameters for density cubes; however, the density measurements was taken via manual measurement with a scale and micrometer which cannot achieve the precision desired for measuring near fully dense parts (Pohl, 2019). As shown in Figure 21, the manual measurements recorded the maximum relative density to be less than $95 \%$ when selective laser melting has been shown capable of achieving over 99\% relative density (Kamath et al., 2013).

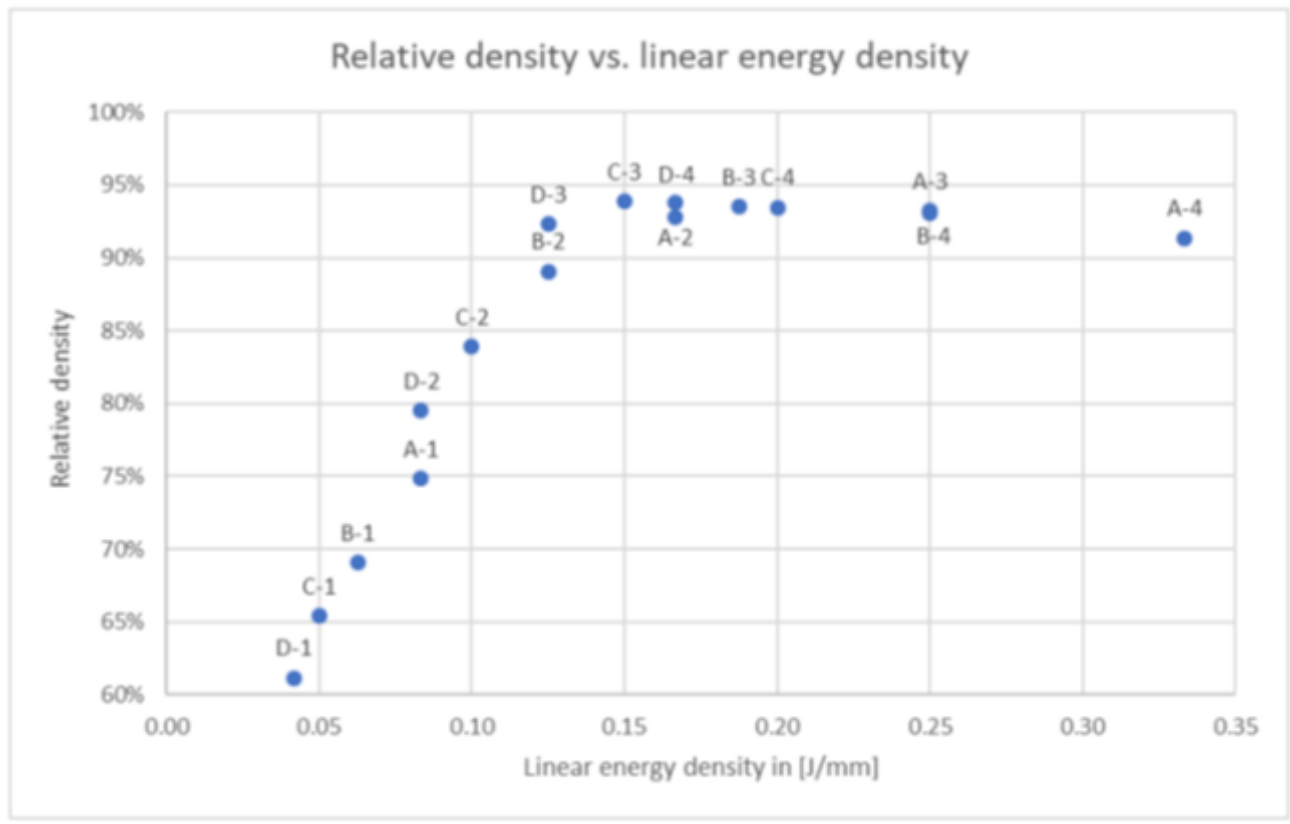

Figure 21. Relative density of $8 \times 8 \times 8 \mathrm{~mm}$ cubes taken with micrometer and digital scale (Pohl, 2019).

This level is too large when it is important to be able to differentiate at a level of $\pm 1 \%$ because the difference between $97 \%$ and $98 \%$ can make a significant difference. The objective of this experiment is to vary the density measurement method as well as the size of the density cube to determine if the precision of the density results can be improved.

\subsection{Experimental Procedure}

The density cubes for the past thesis were all $8 \times 8 \times 8 \mathrm{~mm}$ which is smaller than typically seen in density cube studies (Yakout, Elbestaawi, and Veldhuis, 2019 and Spierings and Levy, 2009 and Kruth et al., 2005). Because the purpose of this study is to examine the 
effect of larger density cubes have on the consistency of measurements, cubes will range from $12 \mathrm{~mm}$ to $30 \mathrm{~mm}$ side length. From previous prints with this machine and simulation through Netfabb, it was expected that the $30 \mathrm{~mm}$ sample would be near the limit of what could be successfully printed. At a certain point, the support structure can no longer dissipate the heat well enough and the residual stresses will cause the part to warp upward (Mervelis and Kruth, 2006). Figure 22 displays warpage around the bottom of the part nearing $1 \mathrm{~mm}$.
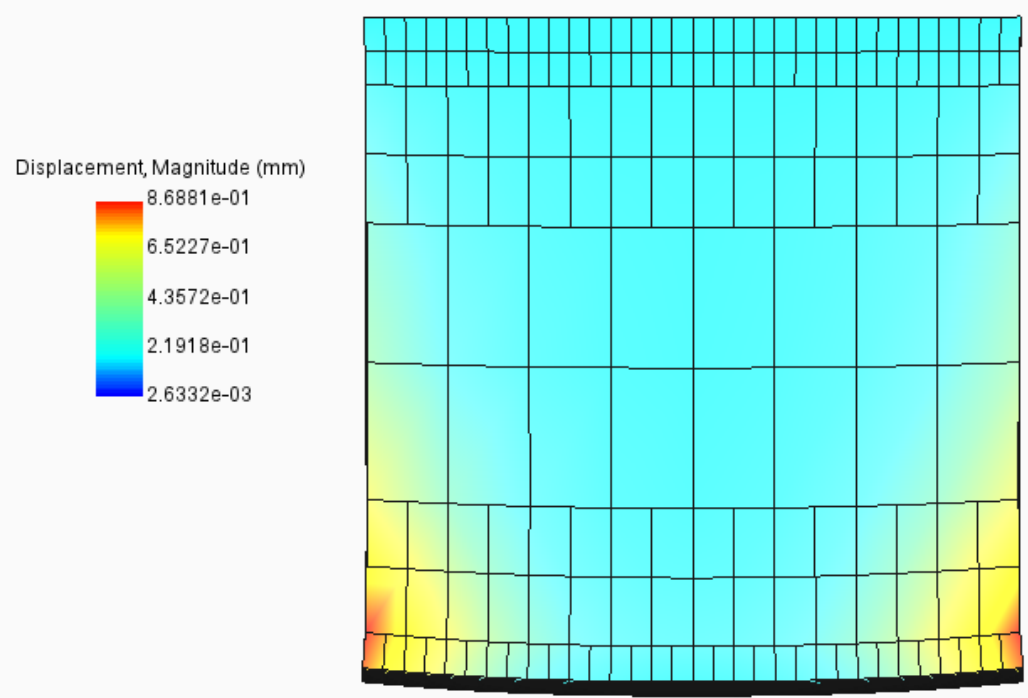

Figure 22. Netfabb simulation of 30x30x30mm density sample with warpage around bottom

It should be noted that the version of Netfabb being used prevented the creation of new materials, so the part was modeled as a cobalt-chromium alloy with similar thermomechanical properties to $316 \mathrm{~L}$ stainless steel. The goal was to achieve a rough estimate for when warpage would begin to cause problems, so the error introduced was deemed acceptable. The parts will be printed with the following machine parameters in accordance with a previous on campus study which tested density cubes at a range of laser powers and scan speeds.

Laser Power: $150 \mathrm{~W}$

Scan Speed: $1000 \mathrm{~mm} / \mathrm{s}$

Hatch Distance: $120 \mu \mathrm{m}$

Spot Size: $70 \mu \mathrm{m}$ 


\section{Print Pattern: Stripe}

After the parts have been printed, they will be removed from the build plate, have the remaining support structure ground off. Next the parts will be cut to expose their cross sections each which will be used to reach an average porosity for each.

\subsection{Analysis}

Even while the cubes were still on the build plate, we were able to see the warpage and cracking at the edges of the larger cube as shown in Figure 23.

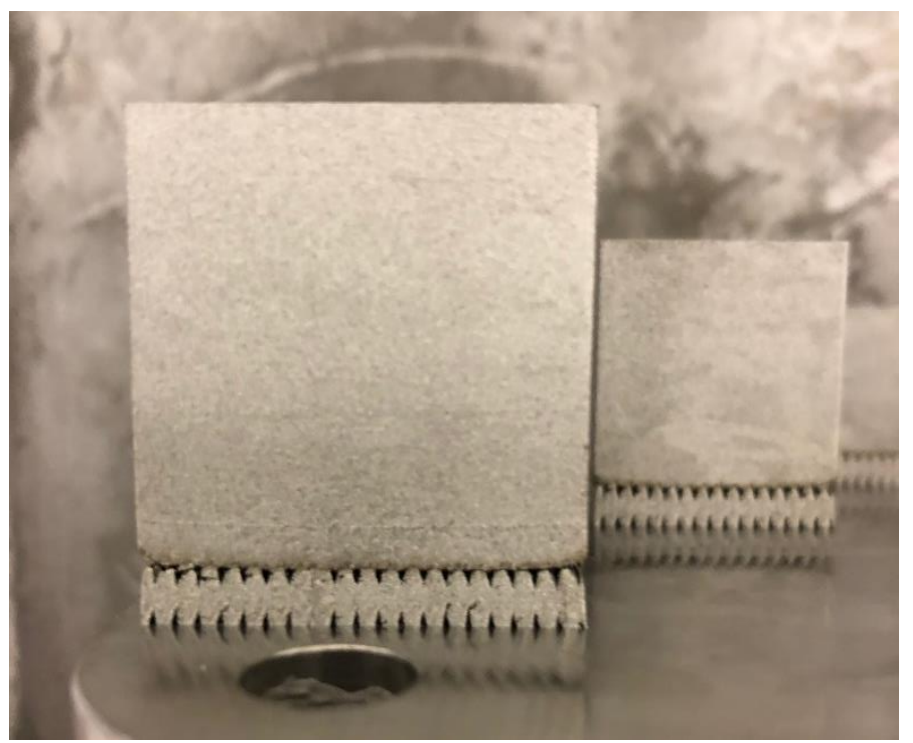

Figure 23. Warpage of 30x30x30mm density cube sample.

In addition, even the smaller samples show visible defects in the bottom part of the sample. The cause of this lack of complete solidification is unclear, but it may be due to the scan pattern or support structure (Mahmoud and Elbestawi, 2018). The small samples with defects are shown in Figure 24. 


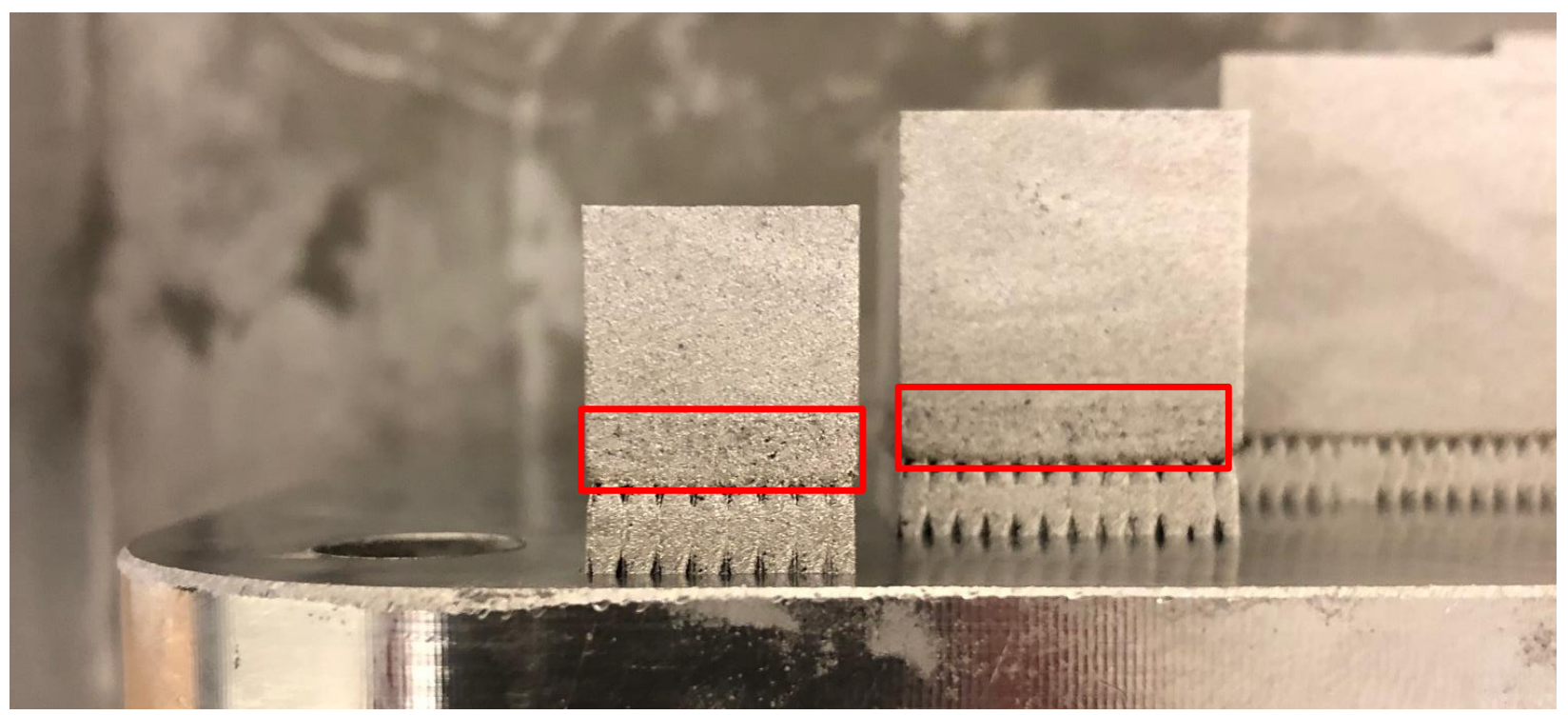

Figure 24. Small density samples with porosity defect in lower portion.

Because the defects on each of the parts were small relative to the size of the entire sample, the defective areas were neglected from the micrographs chosen for inspection.

Then density cube samples were analyzed using micrograph analysis of the vertical cross sections. A. B. Spierings and G. Levy (2009) noted that the cross section in the XZ or YZ plane will be more representative of the total volume than an XY cross section because multiple layers will be exposed. The images are taken at 100x magnification and varied in the $\mathrm{Z}$ direction to view detail at many layers. One challenge faced in the determination of porosity was setting the threshold such that pores are included but small scratches are not such as in Figure 25. 


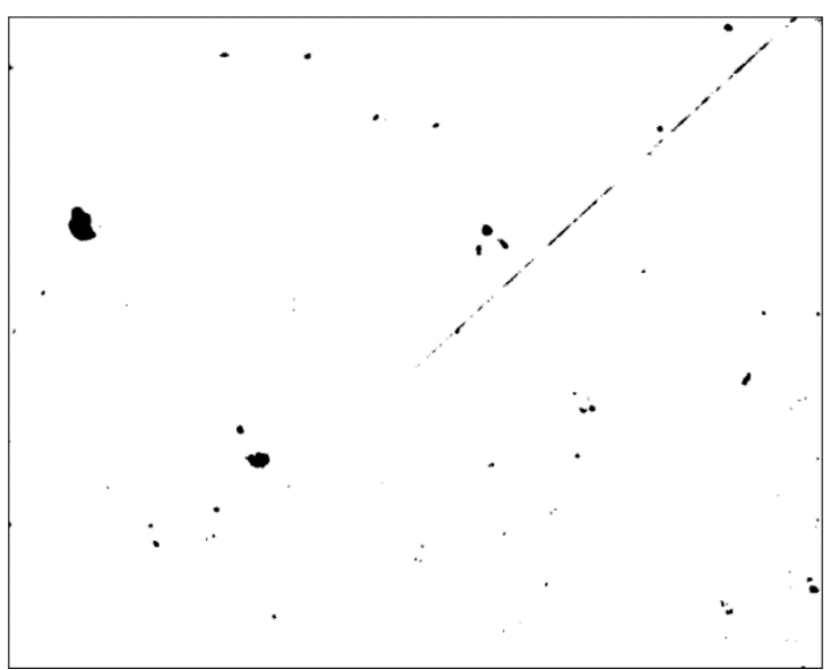

Figure 25. Micrograph from $12 \mathrm{~mm}$ sample with raised threshold that includes scratch running from top right to bottom left.

\subsection{Results and Discussion}

The micrographs taken from the four samples were analyzed using Image $\mathbf{J}$ to estimate the relative density based on the area percent porosity. For each sample, four micrographs were taken across multiple layers and the relative densities were averaged. The results from with method with $95 \%$ confidence intervals based on 4 micrographs per density cube are shown in Figure 26.

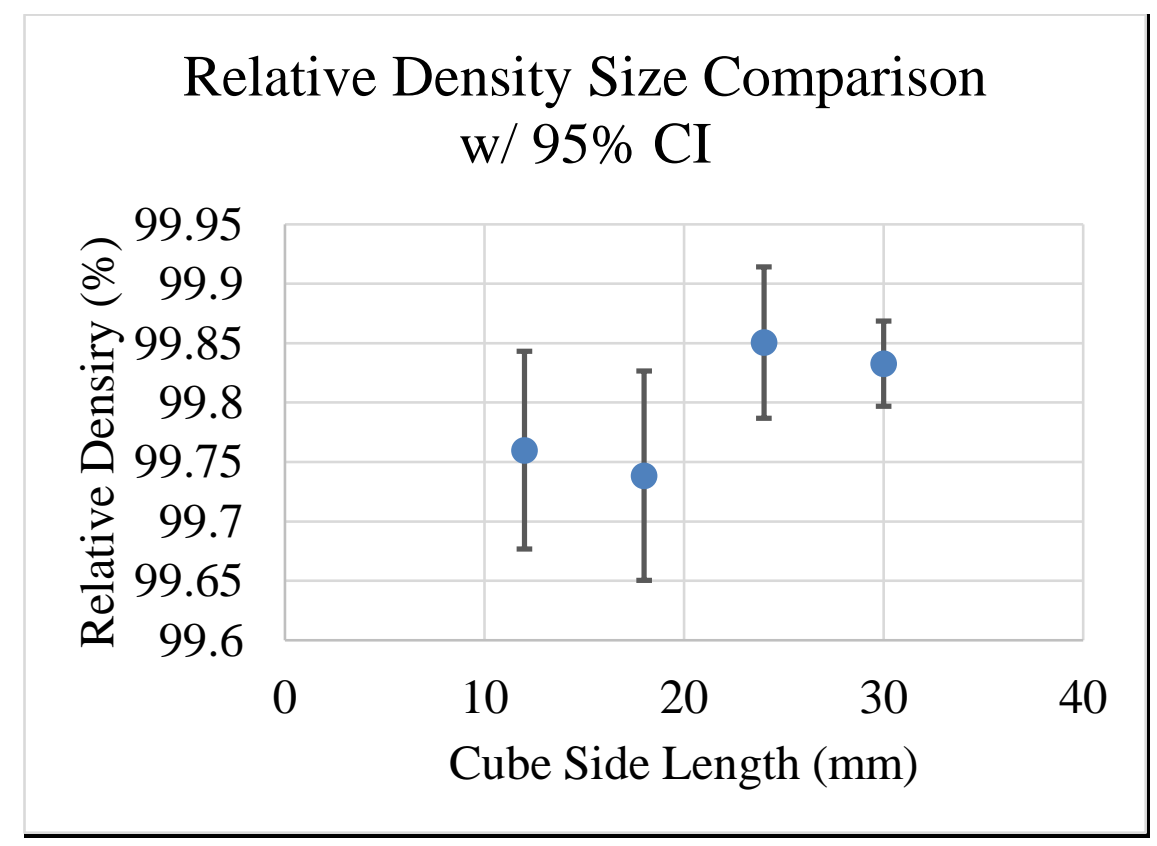

Figure 26. Relative density with $95 \%$ confidence intervals using micrograph analysis.

While the nominal values of the density vary by just over $0.1 \%$, the confidence intervals overlap for each sample. Therefore, none of the relative densities are significantly 
different from each other. From this information we can conclude that the relative density of parts in this size range is likely above $99.5 \%$ and does not vary drastically with change in part volume. This means that the machine should be able to reliably print near fully dense parts are the current operating settings.

The largest confidence interval for these samples is $0.17 \%$ from the $18 \mathrm{~mm}$ sample. This value could be further decreased by taking a large sample size of micrographs to encompass a larger portion of the total cross section. However, a study from LLNL claimed that $>99 \%$ is considered nearly fully dense, so our process parameters appear to be well selected to achieve parts near the limit of SLM capabilities for density (Kamath et al., 2013). 


\subsection{CONCLUSION}

In this study, we showed how we can use simple simulations and single track experiments to guide predictions as to what process parameters will create near fully dense parts with selective laser melting. By examining the melt pools and beads created by the single tracks, we were able to validate the suitable choice of process parameters determined by a previous study and move forward with density cube tests. While we were attempting to create dense parts, these parameters have been tailored by other researchers to achieve a plethora of mechanical and thermal properties.

Our initial simulation with the Eagar-Tsai model provided insight into the rough shape of the melt pool and trends to expect as laser power and scan speed are changed. One of the most important trends observed was the melt pool depth and width within the same linear energy density. The settings with slower scan speeds and lower powers yielded larger melt pools than the equivalent LED at higher speeds and power due to the influence of the velocity term. The final prints confirmed this prediction. However, the simulation consistently predicted smaller melt pools than observed, particularly in the depth. One drawback to the methods used in this experiment was the clarity of single tracks on top of tracks of the support below. This could be remedied by applying upskin to the penultimate layer (re-melting the layer) or polishing that layer before applying the single track layer. In addition, the current operating parameters of $150 \mathrm{~W}$ and $1000 \mathrm{~mm} / \mathrm{s}$ were confirmed to create continuous tracks and melt through greater than 1 layer of powder to create a connection to lower layers.

The density cube experiment confirmed that micrograph analysis provides a readily available, fast, and inexpensive option for measuring density of parts above $99 \%$ within $0.2 \%$. For this particular method, the size of the density cubes did not produce significantly different density values, so the optimized machine settings may be used repeatably across a wide range of cross sections assuming appropriate support structure is used.

While this experiment only touched on the effects of laser power and scan speed, a follow up experiment could test other simple parameters such as layer thickness, spot size, and hatching distance. Ideally, the goal would be to maintain high quality, high density parts 
while using a higher linear energy density to reduce the build time or enhance geometrical accuracy. One area of trouble in this further study would be determining a minimum recoat time for a given cross sectional area because the amount of energy input will be greater. As such, the heat will require more time to dissipate to prevent damaging the recoater blade or introducing excess residual stress. Every print has different goals in mind, different shape, and different size, so the print parameters should eventually be able to reflect the dynamic nature of selective laser melting. 


\section{REFERENCES}

1. An Overview of the Most Common Types of Metal 3D Printing. 3DPrinting.com, https://3dprinting.com/metal/types-of-metal-3d-printing/.

2. ASTM_International (1993/2002), B 311-93/02: Test Method for Density Determination for Powder Metallurgy (PM ) Materials Containing Less Than Two Percent Porosity, ASTM_International, West Conshohocken, PA.

3. ASTM_International (2008), B 962-08: Standard Test Methods for Density of Compacted or Sintered Powder Metallurgy (PM ) Products Using Archimedes' Principle, ASTM_International, West Conshohocken, PA.

4. Badrosamay, M., Yasa, E., van Vaerenbergh, J. and Kruth, J.P. (2009), "Improving productivity rate in SLM of commercial steel powders", paper presented at RAPID 2009 Conference \& Exposition, Schaumburg, IL, 2627 May.

5. Brandt, M., Easton, M., \& Sun, S. (2017). Laser additive manufacturing:

Materials, design, technologies and applications. doi:https://doi.org/10.1016/B978-0-08-100433-3.00002-6

6. Cheng, B., \& Chou, K. (2015). Melt Pool Evolution Study in Selective Laser Melting(Rep.). Retrieved April 28, 2019, from University of Alabama Mechanical Engineering Department website.

7. Di, Wang \& Yongqiang, Yang \& Xubin, Su \& Yonghua, Chen. (2012). Study on energy input and its influences on single-track,multi-track, and multi-layer in SLM. International Journal of Advanced Manufacturing Technology INT J ADV MANUF TECHNOL. 58. 10.1007/s00170-011-3443-y.

8. Dilip, J., Anam, A., Pal, D., \& Stucker, B. (2016). A short study on the fabrication of single track deposits in SLM and characterization. In Solid Freeform Fabrication Symposium. Retrieved January 5, 2019.

9. Dilip, J. J. S., Zhang, S., Teng, C., Zeng, K., Robinson, C., Pal, D., \& Stucker, B. (2017). Influence of processing parameters on the evolution of melt pool, porosity, and microstructures in Ti-6Al-4V alloy parts fabricated by 
selective laser melting. Progress in Additive Manufacturing, 2(3), 157167. https://doi.org/10.1007/s40964-017-0030-2

10. Doubenskaia, M., Grigoriev, S., Zhirnov, I., \& Smurov, I. (2016). Parametric analysis of SLM using comprehensive optical monitoring. Rapid Prototyping Journal, 22(1), 40-50. Retrieved from http://ezproxy.lib.calpoly.edu/login?url=https://search-proquestcom.ezproxy.lib.calpoly.edu/docview/1759344552? accountid=10362

11. Eagar, T., \& Tsai, N. (n.d.). Changes of weld pool shape by variations in the distribution of heat source in arc welding(Rep.). Massachusetts Institute of Technology Department of Materials Science and Engineering.

12. Eagar, T., \& Tsai, N. (1983). Temperature Fields Produced by Traveling Distributed Heat Sources(Rep.). Welding Research Supplement.

13. Gong, H., Teng, C., Zeng, K., Pal, D., Stucker, B., Dilip, J., . . L Lewandowski, J. J. (2016). Single Track of Selective Laser Melting Ti-6Al-4V Powder on Support Structure. In Solid Freeform Fabrication Symposium. Retrieved January 25, 2019.

14. Grylls, R. (2018, March). CSV File Creation [Webinar].

15. Gu D.D. and Shen Y.F. : Balling phenomena during direct laser sintering of multi-component Cu-based metal powder . J. Alloy. Compd. 432 , 163 (2007).10.1016/j.jallcom.2006.06.011

16. Han, J., Yang, J., Yu, H., Yin, J., Gao, M., Wang, Z., \& Zeng, X. (2017).

Microstructure and mechanical property of selective laser melted Ti6Al4V dependence on laser energy density. Rapid Prototyping Journal, 23(2), 217-226.

17. Ihsani, Z., \& Ihsani, Z. (n.d.). Porosity Analysis Procedure with ImageJ. Retrieved May 1, 2019, from https://www.academia.edu/24152953/Porosity_Analysis_Procedure_with_ Image J

18. Kamath, C., El-Dasher, B., Gallegos, G. F., King, W. E., \& Sisto, A. (2013). Density of Additively-Manufactured, 316L SS Parts Using Laser PowderBed Fusion at Powers Up to 400W. doi:10.2172/1116929 
19. Kaynak, Y., \& Kitay, O. (2018). Porosity, Surface Quality, Microhardness and Microstructure of Selective Laser Melted 316L Stainless Steel Resulting from Finish Machining. Journal of Manufacturing and Materials Processing,2(2), 36. doi:10.3390/jmmp2020036

20. Kruth, J.P., Vandenbroucke, B., van Vaerenbergh, J. and Mercelis, P. (2005), "Benchmarking of different SLS/SLM processes as rapid manufacturing techniques", Proceedings of the International Conference on Polymers \& Moulds Innovations (PMI), Gent, Belgium, 20-23 April.

21. Lecoanet, A., Ivey, D. G., \& Henein, H. (2014). Simulation of the Temperature Profile During Welding with COMSOL Multiphysics® Software Using Rosenthal's Approach. In 2014 COMSOL Conference. Retrieved April 28, 2019.

22. Liu, J., Jalalahmadi, B., Guo, Y. B., Sealy, M. P., \& Bolander, N. (2018). A review of computational modeling in powder-based additive manufacturing for metallic part qualification. Rapid Prototyping Journal, 24(8), 1245-1264. doi:http://dx.doi.org.ezproxy.lib.calpoly.edu/10.1108/RPJ-04-2017-0058

23. Mahmoud, D., \& Elbestawi, M. A. (2018). Selective laser melting of porosity graded lattice structures for bone implants. The International Journal of Advanced Manufacturing Technology,100(9-12), 2915-2927. doi:10.1007/s00170-018-2886-9

24. Mercelis, P., \& Kruth, J. (2006). Residual stresses in selective laser sintering and selective laser melting. Rapid Prototyping Journal, 12(5), 254-265. doi:http://dx.doi.org.ezproxy.lib.calpoly.edu/10.1108/1355254061070701 3

25. Monroy, K., Delgado, J., Sereno, L., Ciurana, J., \& Hendrichs, N. J. (2015). Geometrical feature analysis of co-cr-mo single tracks after selective laser melting processing. Rapid Prototyping Journal, 21(3), 287-300.

26. National Institute of Standards and Technology (2013) Measurement Science Roadmap for Metal-Based Additive Manufacturing. Washington, D.C., USA. 
27. Perevoshchikova, N., Rigaud, J., Sha, Y., Heilmaier, M., Finnin, B., Labelle, E., $\& \mathrm{Wu}$, X. (2017). Optimisation of selective laser melting parameters for the ni-based superalloy IN-738 LC using doehlert's design. Rapid Prototyping Journal, 23(5), 881-892.

28. Petri Laakso, Tuomas Riipinen, Anssi Laukkanen, Tom Andersson, Antero Jokinen, Alejandro Revuelta, Kimmo Ruusuvuori, Optimization and Simulation of SLM Process for High Density H13 Tool Steel Parts, Physics Procedia, Volume 83, 2016, Pages 26-35, ISSN 1875-3892, https://doi.org/10.1016/j.phpro.2016.08.004.

29. Pohl, S. (2019). Improving Printing Quality by Optmizing Linear Energy Density in Selective Laser Melting and Demonstrating its Inherent Constraints. Munich University of Applies Sciences, Munich, Germany.

30. Rabilah, Rosniza \& Wahab, Noraini \& Omar, mohd afian \& Ria Jaafar, Talib \& Budin, Salina \& Mardini Hashim, Siti \& Sauti, Rosliza \& Abdul Razak, Mustaqim. (2017). Physical and mechanical properties of injection moulded 316L stainless steel using waste rubber binder. AIP Conference Proceedings. 1901. 130022. 10.1063/1.5010582.

31. Spears, T. G., \& Gold, S. A. (2016). In-process sensing in selective laser melting (SLM) additive manufacturing. Integrating Materials and Manufacturing Innovation, 5(1). https://doi.org/10.1186/s40192-016-0045-4

32. Spierings, A.B. and Levy, G. (2009a), "Comparison of density of stainless steel 316L parts produced with selective laser melting using different powder grades", Proceedings of the Annual International Solid Freeform Fabrication Symposium, Austin, TX, USA, 3-5 August, p. 20.

33. Spierings, Adriaan \& Schneider, M \& Eggenberger, R. (2011). Comparison of Density Measurement Techniques for Additive Manufactured Metallic Parts. Rapid Prototyping Journal. 17. 380-386.

$10.1108 / 13552541111156504$.

34. Uddin, S. Z., Murr, L. E., Terrazas, C. A., Morton, P., Roberson, D. A., \& Wicker, R. B. (2018). Processing and characterization of crack-free aluminum 6061 using high-temperature heating in laser powder bed fusion 
additive manufacturing. Additive Manufacturing,22, 405-415. doi:10.1016/j.addma.2018.05.047

35. Yadroitsev, I., Yadroitsava, I., Bertrand, P., \& Smurov, I. (2012). Factor analysis of selective laser melting process parameters and geometrical characteristics of synthesized single tracks. Rapid Prototyping Journal, 18(3), 201-208. doi:http://dx.doi.org.ezproxy.lib.calpoly.edu/10.1108/1355254121121811 7

36. Yakout, M., Elbestawi, M., \& Veldhuis, S. C. (2019). Density and mechanical properties in selective laser melting of Invar 36 and stainless steel 316L. Journal of Materials Processing Technology,266, 397-420. doi:10.1016/j.jmatprotec.2018.11.006

37. Zhang, L., Zhu, H., Liu, J., \& Zeng, X. (2018). Track evolution and surface characteristics of selective laser melting Ti6A14V. Rapid Prototyping Journal, 24(9), 1554-1562.

doi:http://dx.doi.org.ezproxy.lib.calpoly.edu/10.1108/RPJ-01-2018-0004 
APPENDIX A: SOP FOR CREATING A CUSTOMIZED TOP LAYER

\begin{tabular}{|c|c|c|}
\hline Step & Directions & Image \\
\hline 1 & $\begin{array}{l}\text { Create part with correct } \\
\text { top layer geometry }\end{array}$ & \\
\hline 2 & Import part into MCS & \\
\hline 3 & $\begin{array}{l}\text { Export top layer as text } \\
\text { file }\end{array}$ & \\
\hline 4 & $\begin{array}{l}\text { Open the text file and } \\
\text { delete the "Coordinates } \\
\text { for Layer___"line }\end{array}$ & $\begin{array}{l}\text { Cullen_ST_108- Notepad } \\
\text { File Edit Format View Help } \\
\text { Coordinates for Slice } 108 \\
\text { Laser Power: } 50.000000 \\
\text { Scanner Speed: } 400.000000 \\
\text { Focus Position: } 0.000000 \\
\text { Jump: -52.435501, } 29.068899 \\
\text { Mark: -37.682098, } 29.069000\end{array}$ \\
\hline 5 & $\begin{array}{l}\text { Edit speeds, powers, and } \\
\text { scan dimensions }\end{array}$ & $\begin{array}{l}\text { Cullen_ST_108- Notepad } \\
\text { File Edit Format View Help } \\
\text { Laser Power: } 50.000000 \\
\text { Scanner Speed: } 400.000000 \\
\text { Focus Position: } 0.000000 \\
\text { Jump: -52.435501, } 29.068899 \\
\text { Mark: }-37.682098,29.069000\end{array}$ \\
\hline 6 & $\begin{array}{l}\text { Import data into CSV } \\
\text { Converter spreadsheet }\end{array}$ & 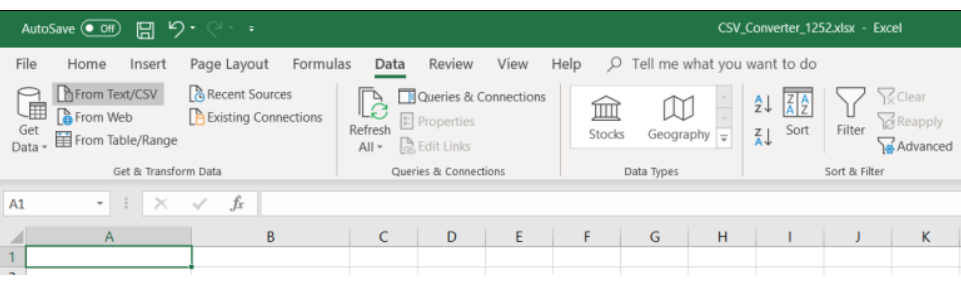 \\
\hline
\end{tabular}




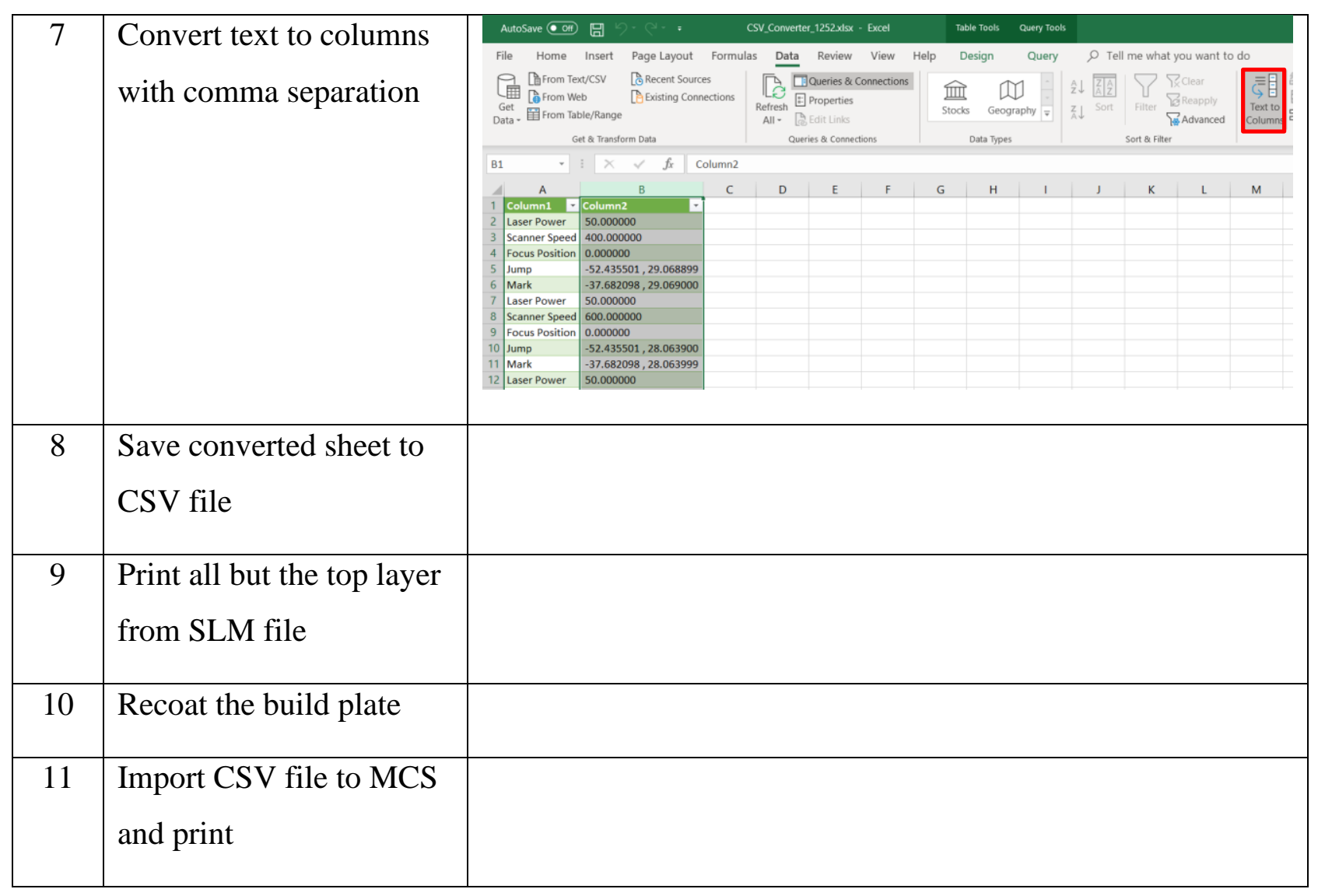


APPENDIX B: FULL TABLE OF SINGLE TRACK DEPTH AND WIDTH DATA

\begin{tabular}{|c|c|c|c|c|c|c|c|c|}
\hline \multicolumn{9}{|c|}{ Single Track Widths $(\mu \mathrm{m})$} \\
\hline & & \multicolumn{7}{|c|}{ Scan Speeds $(\mathrm{mm} / \mathrm{s})$} \\
\hline & & 400 & 600 & 800 & 1000 & 1200 & 1400 & 1600 \\
\hline \multirow{6}{*}{ 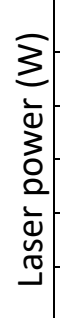 } & 50 & & & & & & & \\
\hline & 100 & 106 & 101 & & & & & \\
\hline & 150 & 134 & 129.5 & 93 & 108 & & & \\
\hline & 200 & 121 & 110 & 112 & 93 & 93 & 86 & 65 \\
\hline & 250 & 127 & 125 & 108 & 119 & & & \\
\hline & 300 & 127 & 155 & 111 & 90 & 111 & 98 & \\
\hline
\end{tabular}

\begin{tabular}{|c|c|c|c|c|c|c|c|c|}
\hline \multicolumn{9}{|c|}{ Single Track Depths $(\mu \mathrm{m})$} \\
\hline & & \multicolumn{7}{|c|}{ Scan Speeds $(\mathrm{mm} / \mathrm{s})$} \\
\hline & & 400 & 600 & 800 & 1000 & 1200 & 1400 & 1600 \\
\hline \multirow{6}{*}{ 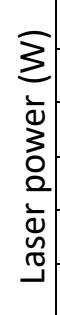 } & 50 & & & & & & & \\
\hline & 100 & 86 & 53 & & & & & \\
\hline & 150 & 358 & 232 & 121 & 121 & & & \\
\hline & 200 & 251 & 194 & 151 & 111 & 54 & 53 & 58 \\
\hline & 250 & 190 & 181 & 71 & 97 & & & \\
\hline & 300 & 440 & 234 & 200 & 164 & 186 & 116 & \\
\hline
\end{tabular}

